\title{
Role of Metallurgy in the Localized Corrosion of Carbon Steel
}

\author{
Recep Avci*, Bret H. Davis, Nathaniel Rieders, Kilean Lucas, Manjula Nandasiri, Dave Mogk \\ Imaging and Chemical Analysis Laboratory, Montana State University, Bozeman, MT, USA \\ Email: ^avci@montana.edu
}

How to cite this paper: Avci, R., Davis, B.H., Rieders, N., Lucas, K., Nandasiri, M. and Mogk, D. (2018) Role of Metallurgy in the Localized Corrosion of Carbon Steel. Journal of Minerals and Materials Characterization and Engineering, 6, 618-646. https://doi.org/10.4236/jmmce.2018.66044

Received: October 9, 2018

Accepted: November 19, 2018

Published: November 23, 2018

Copyright (c) 2018 by authors and Scientific Research Publishing Inc. This work is licensed under the Creative Commons Attribution International License (CC BY 4.0).

http://creativecommons.org/licenses/by/4.0/

\begin{abstract}
Localized residual strain develops within the metallurgical texture of 1018 carbon steel from metallurgical processes, such as fabrication, annealing, and shaping. This residual strain results in accelerated localized pitting due to the formation of anodic sites at these locations. Once initiated, micron-sized corrosion pits can coalesce to form sites of potential catastrophic failure. In this contribution, we focus on the localized biocorrosion which initiates and grows in areas of localized strain such as the interfaces between manganese sulfide (MnS) inclusions and ferrite grains in the steel, at grain boundaries between ferrite grains with different crystallographic orientations and at pearlite grains (intergrown cementite $\left(\mathrm{Fe}_{3} \mathrm{C}\right)$ and ferrite), which are readily found in 1018 carbon steel. Here we hypothesize and show experimentally that accelerated biocorrosion in 1018 carbon steel finds its roots in the electrochemical potential difference (micro galvanic cells) generated between the unstrained ferrite iron $(\alpha-\mathrm{Fe})$ and the lattice defects, dislocations and mismatches found at interfaces formed between $\alpha-\mathrm{Fe}$ and secondary phases i.e. MnS inclusions, cementite lamellar structures and grain boundaries distributed throughout the 3D network of the carbon steel. This hypothesis is supported by results from multiple micro- and nanoscale imaging and analytical methods obtained from field emission scanning electron microscopy, energy dispersive spectroscopy, electron backscattered diffraction and Auger nanoprobe electron spectroscopy. The morphology and composition of grains in the steel coupons were characterized before and after exposure to suboxic and sulfidogenic environments dominated by aerobic and anaerobic marine organisms. Corrosion processes are demonstrated to initiate in localized areas of high residual strain.
\end{abstract}

\section{Keywords}

Metallurgy, Strain, Dislocations, Carbon Steel, Micro Galvanic Cell, Suboxic, Sulfidogenic, MnS, Pearlite, Cementite, Grain Boundary 


\section{Introduction}

Low-carbon steels have a commanding presence in our society because of the near universality of steel as a building material in historical and modern infrastructures. Its degradation and eventual failure due to corrosion are of great concern and costly; the annual direct and indirect cost of corrosion in the USA is $\sim 6 \%$ of the US gross national product, $\sim 1$ trillion dollars [1] [2]. Often the failure in a piece of steel is due not to loss of metal caused by generalized corrosion, but to localized destruction of metal caused by accelerated corrosion. In practice, metals are alloyed with appropriate elements to increase their strength, malleability and weldability, which inherently creates dislocations and inclusions in the crystal matrix; this causes a distribution of localized plastic deformations in the lattice. This residual strain creates enhanced anodic sites, where the constituent metal atoms are more susceptible to dissolution and subsequent localized corrosion [3] [4] [5]. We investigated three very important examples of localized corrosion on the surface of 1018 carbon steel coupons: 1) the immediate surroundings of manganese sulfide (MnS) inclusions, 2) grain boundaries between grains of different crystallographic orientations, and 3) ferrite layers in and around pearlite lamellae. These are all examples of sites of lattice defects and strains that developed during the metallurgical processing of the metal. Such metallurgical nano/microstructures play a detrimental role in the localized corrosion of carbon steel. Any coating technology, be it polymer paints, next generation thin films such as graphene, passive layers or corrosion inhibitors, must coat these structures at the nanoscale in order to prevent localized corrosion.

\section{Brief Review of Carbon Steel Metallurgy in Relation to This Work}

To examine the impact that $\mathrm{MnS}$, pearlite, and grain boundaries, herein referred to as "microstructures", have on the corrosion of low-carbon steel (0.05- 0.25 $\mathrm{wt} \% \mathrm{C}$ ), one must begin with the metallurgical history of the steel, in particular of carbon steel, which starts as iron ore which is reduced, purified, heat-treated and alloyed with a small amount of impurities (most notably carbon and Mn) to control its hardness, malleability, ductility, weldability and tensile strength [6] [7]. The formation of microstructures during fabrication is controlled by three primary factors: 1) the chemical composition (weight percent of carbon, sulfur impurity, and $\mathrm{Mn}$ ); 2) the temperature history (heating and annealing) of the steel; and 3) the metalworking (cold and hot rolling) history.

Steel fabrication begins with iron ore, consisting primarily of iron oxides (e.g. taconite), that is mined from the Earth. The ore also contains various other mineral oxides such as silica and alumina. Iron ore must be crushed, treated by removing irrelevant and unwanted minerals and made into pellets before being subjected to the reduction process [8]. Historically, this has been done by heat treatment in blast furnaces, which facilitates the oxidation of carbon and reduction of iron. The processed ore can also be reduced without melting through direct reduction techniques. The blast furnace approach involves a blend of 
crushed iron ore, treated coal (or metallurgical coke, which is a purified carbon with minor pollutants), and limestone (i.e. $\mathrm{CaCO}_{3}$ ). These three components are carefully fed into the blast furnace to reduce and purify the iron oxides. The blast furnace is a hot, pressurized environment enabled by the oxidation of $\mathrm{C}$ reacting with $\mathrm{O}_{2}$ in the hot air blowing into the mixture. This provides an environment for endothermic reactions, such as $\mathrm{Fe}_{2} \mathrm{O}_{3}+3 \mathrm{C} \rightarrow 2 \mathrm{Fe}+3 \mathrm{CO}$, which scavenges $\mathrm{O}$ from $\mathrm{Fe}_{2} \mathrm{O}_{3}$, reducing the $\mathrm{Fe}^{3+}$ to its elemental form. The $\mathrm{C}$ in the coke has two functions: it reacts with the $\mathrm{O}_{2}$ in the hot air and produces heat as a result of exothermic reaction $2 \mathrm{C}+\mathrm{O}_{2} \rightarrow 2 \mathrm{CO}$, and it reacts with iron oxides to reduce the iron to its elemental form. During this step many of the impurities separate from the resultant molten iron mixture in their own solid or liquid phase, collectively referred to as "slag," and float over the molten iron. Meanwhile, the semi-clean iron obtained during this intermediate state, called "molten" or "pig" iron, is collected separately for the next step of purification. The most important next step of refinement takes place in the basic oxygen furnace. At this stage molten iron mixed with recycled steel is subjected to further purification and refining by pure hot oxygen being blown into the mixture of molten iron and lime flux at temperatures reaching $\sim 1600^{\circ} \mathrm{C}$. This oxidizes and removes $\mathrm{S}, \mathrm{P}, \mathrm{C}, \mathrm{Si}$ and other impurities left behind in the pig iron. Subsequently, purified liquid Fe is subjected to ladle metallurgy, in which the quality of the final product is controlled through the addition of appropriate alloying elements (such as $\mathrm{C}$ ) and sulfur scavengers such as $\mathrm{Mn}$ that react with the unwanted S from the steel matrix. The final product (in the molten state) is treated further with inert gasses in a vacuum tank to remove remaining dissolved air gasses from the molten steel. The resultant steel is cast into steel blocks for further hot and cold rolling processing.

During the solidification process $\mathrm{Mn}$ and $\mathrm{S}$ combine into highly malleable $\mathrm{MnS}$ inclusions. These inclusions turn into long, thin MnS stringers during the hot rolling process. $\mathrm{Cu}_{2} \mathrm{~S}$ inclusions also form long, thin stringers. These have serious implications for pitting corrosion as discussed below. Subsequent hot rolling of steel gives the end product its shape, be it sheet metal or a steel bar. In some cases, before it becomes a finished product steel is subjected to cold working (cold rolling) to improve thickness tolerance, ductility and hardness. There are a large number of carbon steels, classified broadly as low-carbon, mild carbon and high-carbon steels. Very high-carbon steels (cast iron) are too hard and brittle to be considered ductile enough for structural applications. The majority of steels used in industry are low-carbon steels containing up to $0.25 \mathrm{wt} \% \mathrm{C}$. The work reported in this manuscript corresponds to 1018 carbon steel containing $\sim 0.18 \mathrm{wt} \%$ carbon. The annealing and cold working of carbon steel determine its hardness and ductility, as well as the formation of pearlite bands in the finished product [6].

The presence of sulfur in steel is one of the persistent issues in steel refining because it has deleterious effects that compromise the mechanical integrity of 
the metal, giving rise to red-short, hot-short or sulfur embrittlement. For example, it has been shown that plastic failure increases with increasing sulfur content [9]. This is dealt with in the desulfurizing step in iron refining mentioned above and by trapping residual sulfur in less soluble inclusions such as MnS [9]. To date, the most effective scavenger of sulfur that does not compromise the mechanical integrity of the steel is manganese; calcium and copper are other favored sulfur-trapping elements. Manganese is added in excess of sulfur by a factor of at least 15 - 30 in low-carbon steels, and even more in specially desulfurized steels.

During the final stages of the hot rolling and annealing process, the metal is transformed from the austenitic $(\gamma-\mathrm{Fe})$ to the ferrite $(\alpha-\mathrm{Fe})$ phase at around $727^{\circ} \mathrm{C}$. The importance of this transition is that in $\gamma$-Fe the $\mathrm{C}$ occupies the interstitial positions in the fcc lattice, while in $\alpha$-Fe the $\mathrm{C}$ atoms segregate into pearlite phases [10]. Here, the $\mathrm{C}$ is locked into the $\mathrm{Fe}_{3} \mathrm{C}$ cementite structure in the form of the lamellar structure of the pearlite phase. Pearlite is made up of repeated submicron-thick layers of cementite and ferrite lamellae. The ferrite structure in pearlite is expected to be highly strained because of lattice mismatch and the presence of large surface areas of cementite/ferrite interfaces. In fact, we hypothesize that pearlite phases are highly strained and are susceptible to localized corrosion [11]. The rate of cooling during the rolling process is one of the many factors that dictate what microstructure will form in the metal and how it will do so, which in turn determine many of the mechanical and corrosion properties of the steel. For example, pearlite bands, often observed in low-carbon steel, are formed during the hot rolling process, as the steel transitions from the austenite to the ferrite phase. Under the high pressure of the rolling process, pearlite bands stretch along the rolling axis, as do MnS inclusions at higher temperatures [12].

Figure 1 shows a Fe-C phase diagram of carbon steel within the carbon content of interest. The 1018 carbon steel has an alloying carbon concentration of 0.18 weight percent, as marked by the dotted vertical line in the figure. If we follow this line vertically at high temperatures, we see that when solid steel is white hot (approximately $1200^{\circ} \mathrm{C}$ ) it is in the austenitic phase, the fcc structure of $\gamma$-Fe. When hot rolled at these temperatures, iron is in the $\gamma$ phase and the highly malleable $\mathrm{MnS}$ inclusions are stretched along the rolling axis into stringers, because the $\mathrm{MnS}$, with a melting temperature of about $1617^{\circ} \mathrm{C}$, has already solidified. However, it is a different story for the $\mathrm{C}$, which, because of the large size of the fcc lattice of the $\gamma$-Fe, is distributed interstitially in the austenite lattice, diffusing randomly in the lattice with no particular order. As the steel cools down slowly, maintaining a quasi-thermodynamic equilibrium, it starts forming islands of ferrite iron (also known as $\alpha$-Fe), a body-centered cubic (bcc) structure with a smaller lattice size, when it reaches about $868^{\circ} \mathrm{C}$. The $\alpha$-Fe phase cannot accept much $\mathrm{C}$ interstitially because of the smaller lattice size. Therefore, in the temperature range between $868^{\circ} \mathrm{C}$ and $727^{\circ} \mathrm{C}$ the carbon steel is a mixture of 


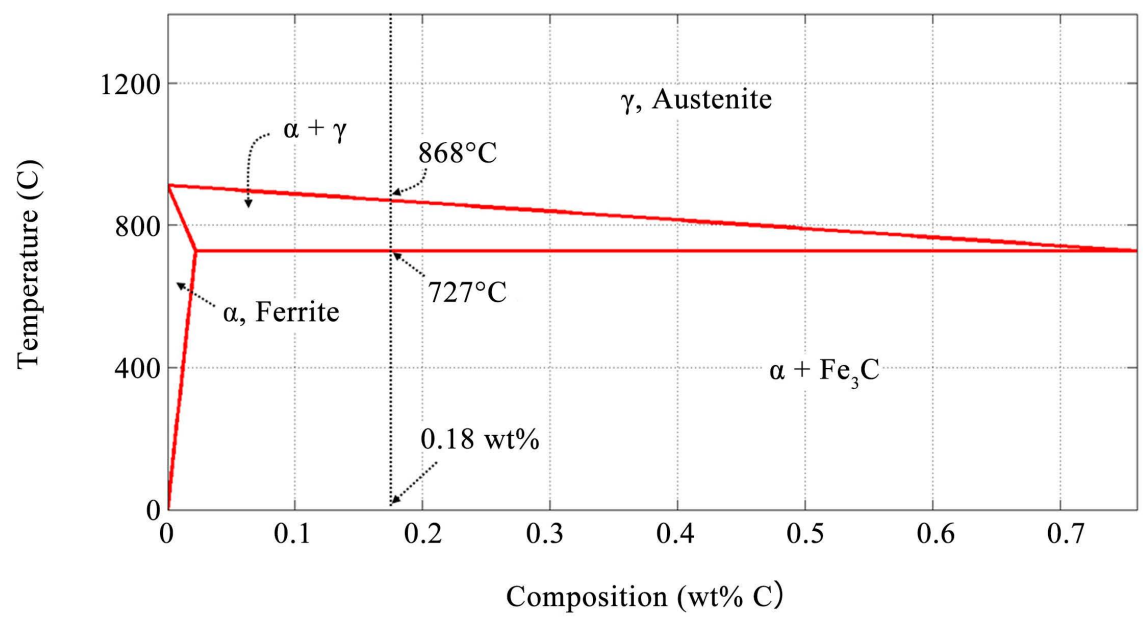

Figure 1. Iron-carbon phase diagram for a hypoeutectoid steel $(<0.76 \mathrm{wt} \%$ carbon $)$ for temperatures below the liquidus line. The composition of 1018 steel ( $0.18 \mathrm{wt} \%$ carbon) is indicated by a dashed line. The two iron/carbon phases (i.e. austenite and ferrite) are indicated, as are important phase transition temperatures pertaining to 1018 steel.

$\alpha$-Fe and $\gamma$-Fe whose composition is determined by lever rule. Most of the $\mathrm{C}$ is randomly distributed in the $\gamma$-Fephase, which is distributed interstitially in the fcc lattice; some of the $\mathrm{C}$ may already have started forming the carbide phase and be residing in the $\alpha$-Fe. However, when the temperature is reduced slowly below $727^{\circ} \mathrm{C}$, where there is no $\gamma$-Fe left in the mixture and all the Fe is now bcc $\alpha$-Fe, the majority of the carbon atoms are locked into the pearlite phase, a mixture of $\mathrm{Fe}_{3} \mathrm{C}$ (iron carbide) layers and $\alpha$-Fe iron layers with submicron-thick lamellar structures. Depending on the temperature, very limited amounts of $\mathrm{C}$ reside interstitially in the $\alpha$-Fe; these are eventually reduced to a negligible amount as the temperature approaches room temperature. At this temperature almost all the carbon in low-carbon steel is locked into the $\mathrm{Fe}_{3} \mathrm{C}$ (cementite) phase. Cementite is a very hard carbide, and in alternating layers with strained ferrite [3] [4] [5] produces the well-known pearlite lamellar structure. In this manuscript we make a distinction between the two ferrite phases in the carbon steel; the thin layers of ferrite phase squeezed between two $\mathrm{Fe}_{3} \mathrm{C}$ cementite layers are expected and hypothesized to be highly strained because of lattice mismatch between the bcc $\alpha$-Fe and the orthorhombic cementite structure. While the ferrite crystals making up the majority of the steel will be relaxed within the grains, atoms residing at the grain boundaries will be strained because of lattice mismatch. These two ferrite structures (strained and unstrained) corrode at different rates as will be shown below.

The immediate surroundings of $\mathrm{MnS}$ inclusions are primary centers of pitting corrosion [3] [4], and it is worthwhile to investigate their origins. Unfortunately it is difficult to remove all the $S$ from steel at a reasonable cost, which would ameliorate the corrosion. The origins of sulfur contamination in carbon steel can be traced to the coke used in its production. The next best approach, as stated above, is to scavenge S using appropriate metal atoms such as Mn. As molten 
steel cools and solidifies, MnS inclusions are formed at a number of stages and in a variety of morphologies [12]-[21]. These sulfide inclusions form where the matrix is most amenable to their presence because of coherency between the phases of the inclusion and the surrounding iron matrix. The precise details of this are largely controlled by the temperature history and chemical composition of the steel, especially its sulfur concentration. The precipitation behavior of manganese sulfide in mild carbon steel is discussed by Ito et al. [16]. The various forms of $\mathrm{MnS}$ inclusions precipitate at different stages during the metallurgical process and nucleate at specific sites as well as exhibiting unique physical characteristics in terms of size and shape. Work conducted on some of the MnS inclusions in our 1018 carbon steel coupons suggests the phase of some of these inclusions is fcc cubic symmetry belonging to space group (SG) 255 with m3m symmetry.

Here, the term "MnS inclusions" has been adopted loosely to describe secondary phases whose elemental composition is dominated by Mn and S. A comprehensive characterization of these inclusions has been lacking. Investigations of the surface and bulk composition, as well as considerations of crystalline structure and the identification of phases, show that these inclusions are complex and heterogeneous. The bulk composition of these inclusions was found in many cases to include $\mathrm{Cu}, \mathrm{Fe}, \mathrm{Ca}, \mathrm{Ti}$ and $\mathrm{Si}$. Surface-sensitive techniques showed that some inclusions are covered with a thin (5-20 nm) layers of copper sulfide, $\mathrm{Mn}$ oxide and FeS, which could result in drastically different electrochemical behavior. It has become clear that the term "MnS inclusion" is a broad generalization. These issues are addressed in our recent work under preparation for publication [22].

Some groups [23] [24] [25] [26] [27] have claimed that it is the size, distribution, and type of MnS inclusions that take shape which will largely determine the corrodibility and strength of the steel. The nucleation and formation of these inclusions occur at austenitic Fe temperatures (recall the melting temperature of $\mathrm{MnS}$ is $1617^{\circ} \mathrm{C}$ ) and before the termination of the hotrolling process.

Consequently, the hotrolling results in the inclusions being stretched into long stringers extending hundreds of microns along the rolling axis [12] [28]. The lattice mismatch between the MnS inclusions and ferrite iron creates long lines of enhanced strain permeating deep into the material along and around the MnS inclusions. Other inclusions such as silicon oxide are less malleable, retain their spherical shape, and do not become elongated along the rolling direction.

Because the $\mathrm{C}$ in $\alpha$-Fe is locked in the carbide phase, cementite starts forming as soon as $\alpha$-Fe forms. When the temperature drops below $725^{\circ} \mathrm{C}$ almost all the carbon in the $\alpha$-Fe is locked in the cementite phase, which appears as pearlite lamellae. It has been argued by Krauss that pearlite prefers to form near elongated MnS inclusions in the iron matrix, in the close surroundings of MnS inclusions [12]. This is not always the case, but our observations show more than the expected number of cases in which MnS inclusions and pearlite bands are 
superimposed along the rolling direction, which has deleterious implications in the corrosion of steel. MnS stringers will form in $\gamma$-Fe (austenite) and persist in $\alpha$-Fe, but pearlite bands can only take form at lower temperatures (below $725^{\circ} \mathrm{C}$ ), where $\alpha$-Fe (ferrite) can exist. After hotrolling, some steels are further cold-worked in order to bring them into final dimensional specifications and improve some metallurgical properties, such as hardness. In some cases, steel can be annealed by heating above the transition temperature (to the $\gamma$-phase) and cooling back slowly to room temperature. Without the help of hot rolling the pearlite structures are expected to be randomly distributed during the $\gamma$ to $\alpha$ transition. Furthermore, the pearlite bands formed during cold rolling at room temperature might not be as distinct as those obtained as a result of hot rolling below the transition temperature $\left(\sim 725^{\circ} \mathrm{C}\right)$.

The three basic microstructures-MnS, pearlite grains, and grain boundaries-all have been known to cause corrosion in the form of pits, cracks or blisters and to contribute to the accelerated localized corrosion of carbon steel. Manganese sulfide inclusions have been observed as crack initiation sites and zones of mechanical weakness [13]. These are attributed to the manganese sulfide inclusions being more plastic than the surrounding iron matrix. Also responsible is weak bonding between the inclusions and the iron matrix.

Manganese sulfide inclusions have been widely reported to be the sites of hydrogen-induced cracking and hydrogen blistering. Luu and $\mathrm{Wu}$ [29] used electrochemical permeation measurements and hydrogen microprint techniques to determine that the main diffusion path of hydrogen in mild carbon steel is along the MnS stringers in the interface between the Fe-lattice and the immediate surroundings of $\mathrm{MnS}$ stringers. Ju and Rigsbee performed a series of experiments [30] [31] [32] in which they cathodically hydrogen-charged low-carbon steels in the absence of external stress, examined the consequent hydrogen damage using scanning electron and optical microscopy, and observed whether or not the microstructure was enhanced within the steel by the heat treatment. They found that damage occurred preferentially at grain boundaries, at the interphase boundary between ferrite and carbide in pearlite, and at the interfaces of ferrite/MnS inclusions. The damage occurred as blisters and cracks. Hydrogen-induced dislocations were found to stack up at the same sites.

Manganese sulfide inclusions have long been documented as being the source of corrosion pitting in carbon steels. Theories have placed pit growth at the manganese sulfide inclusion proper or in the matrix immediately surrounding the inclusion. Gainer [27] suggests a pitting process in carbon steel in neutral chloride solutions in which micropits are initiated at MnS inclusions by the inclusions being anodic to the surrounding matrix. He then further posits that the pitting propagates because of the geometry of the inclusion distribution. Regions of high MnS inclusion density form macropits through the coalescence of multiple micropits. This eventually results in an autocatalytic process in which the macropit continues to grow. Gainer stresses the geometry of the inclusion dis- 
tribution as being the primary contributor to the severity of the pitting. This idea-that the more inclusions there are per unit area, the more severe the corrosion will be in that area-is supported by the work of Sephton [33] and Krauss [12]. Reformatskaya [34] claims that the severity of corrosion at MnS inclusions is dictated by the phase structure of the inclusion and how coherent it is with the surrounding matrix, rather than by the chemical composition of the inclusion. Wranglen [35], too, suggests that "active" inclusions corrode more readily than "inactive" ones. He suggests that pitting is initiated in the matrix immediately surrounding an inclusion by a fine dispersion of sulfide nanoparticles that infects the iron matrix, making it less noble than the inclusion itself and the bulk steel. The pit propagates because a concentration cell is created in the pit that is high in acid and salt and low in oxygen, relative to the bulk solution.

Research on the corrosion of carbon steel around MnS inclusions and at phase boundaries in the crystalline structure (i.e. pearlite and grain boundaries) has largely ignored the residual strains inherent in these structures. Instead, the severity of the corrosion, in the case of MnS inclusions and other sulfides, has been attributed to the chemical composition of the inclusion, the local density of inclusions, or the difference in mechanical properties between the sulfide and the surrounding iron matrix. The facilitation of hydrogen transport at the phase boundaries between inclusions and the iron matrix, or between different phases present in pearlite or at grain boundaries, plays a key role as well. In this manuscript we hypothesize and show experimentally that the unifying concept in all these corrosion processes lies in the imperfections in the ferrite lattice. Residual strain is a fundamental property of the imperfect crystalline structure of metals, full of impurities and inclusions, and the other effects mentioned in the literature largely cascade from this one fundamental fact.

There are a number of ways to prevent localized corrosion in practice. One of these preventive measures is to coat surfaces with polymers or other materials and thin films [36]-[45]. However, these coatings have limited usefulness if the coating material does not cover the surface uniformly at the nanoscale. Locations exposed to a corrosive medium lead to rapid localized corrosion with macroscopic pits. In particular, if the paint does not uniformly coat [37] the surface defects such as MnS inclusions and their immediate surroundings it leads to localized pitting due to exposure to a corrosive environment. The main objective of this paper is to explore the role of metallurgy in the corrosion process. This is accomplished by stripping the corrosion products from the surface and observing changes in the underlying carbon steel. Experiments concerning the rate of corrosion, which is highly dependent on the corrosion medium, will be published elsewhere.

\section{Methods}

We prepared 1018 carbon steel coupons for corrosion experiments by cutting and polishing $\sim 1$-mm-thick slices from $1 / 2$-inch diameter or $1 / 2$-inch-square 
cross-section rods. The slices were cut both parallel and perpendicular to the rolling direction of the rod. The elemental composition of 1018 steel is, by weight percent, $0.14-0.20 \mathrm{C}$, $0.6-0.9 \mathrm{Mn}$, less than $0.04 \mathrm{P}$, and less than $0.05 \mathrm{~S}$, with the balance made up by Fe. The coupons were polished to a final surface roughness of $30-50 \mathrm{~nm}$ using a succession of diamond and silica emulsions, as described in previous work [3] [4] [11]. All chemicals were purchased from Sigma Aldrich. Control coupons such as $99.995 \%$ pure Fe (Alfa Aeser, USA) and $\mathrm{Cu}_{70} \mathrm{Ni}_{30}$ (Qinetic, UK) alloys were cut perpendicular to the bars and polished as described above. All solutions were prepared using Nanopurewater and sterilized by autoclaving (at $\sim 1.5 \times 10^{5} \mathrm{~Pa}$ steam and $120^{\circ} \mathrm{C}$ for $20 \mathrm{~min}$ ) and/or filtering through a $0.1-\mu \mathrm{m}$ filter (Corning Inc.).

The corrosion of the steel coupons was achieved by exposing them to suboxic and sulfidogenic marine environments with a mixed culture of model marine organisms (to simulate conditions expected for Naval vessel hulls and fuel tanks). This culture consisted of aerobic fuel-degrading Marinobacter and anaerobic sulfate-reducing Desulfovibrio indonensiensis incubated in natural seawater. Our experiments were motivated by the need to understand the mechanisms behind the bacteria-influenced corrosion of seawater-compensated fuel ballast tanks in Naval ships in the presence of a marine aerobic and anaerobic bacterial consortium. For this reason, a layer of Naval fuel was also added on top of the natural seawater in our model corrosion reactors. Because various compartments in these fuel tanks are connected with CuNi pipes, we also included a $\mathrm{Cu}_{70} \mathrm{Ni}_{30}$ alloy with the carbon steel in some experiments. The mechanical stability of the ship is maintained by replacing the burned fuel in the fuel tank with filtered seawater. The result is a unique interface formed between a layer of seawater with marine organisms and a layer of Naval fuel sitting on top.

The tops of our reactors were kept open to the atmosphere, and the $\mathrm{O}_{2}$ in the air was in a steady state thermodynamic equilibrium with the dissolved $\mathrm{O}_{2}$ in the fuel and seawater phases. Dissolved $\mathrm{O}_{2}$ in seawater was consumed through one of three mechanisms: 1) aerobic respiration of Marinobacter, 2) oxidation of metallic surfaces or 3) production of thiosulfates by $\mathrm{H}_{2} \mathrm{~S}$ reacting with $\mathrm{O}_{2}$. A schematic of the system is presented in Figure 2. Measurements showed that the oxygen concentration in the seawater was below $50 \mathrm{ppb}$ and remained more or less constant starting $\sim 1 \mathrm{~mm}$ below the seawater/fuel interface (see Figure 2), a suitable condition for mixtures of aerobic and anaerobic species.

\subsection{Corrosion Experiments}

Corrosion experiments were conducted in the reactors described in Figure 2, in which the coupons were exposed to aerobic fuel-degrading Marinobacter and anaerobic, sulfate-reducing Desulfovibrio indonensiensis. Experiments were conducted in an environment with both aerobic and anaerobic bacteria present (herein referred to as suboxic/sulfidogenic) and in an environment with no anaerobic bacteria present as a control (referred to as suboxic). Hence all experiments were conducted in a suboxic environment. The corrosive medium was 


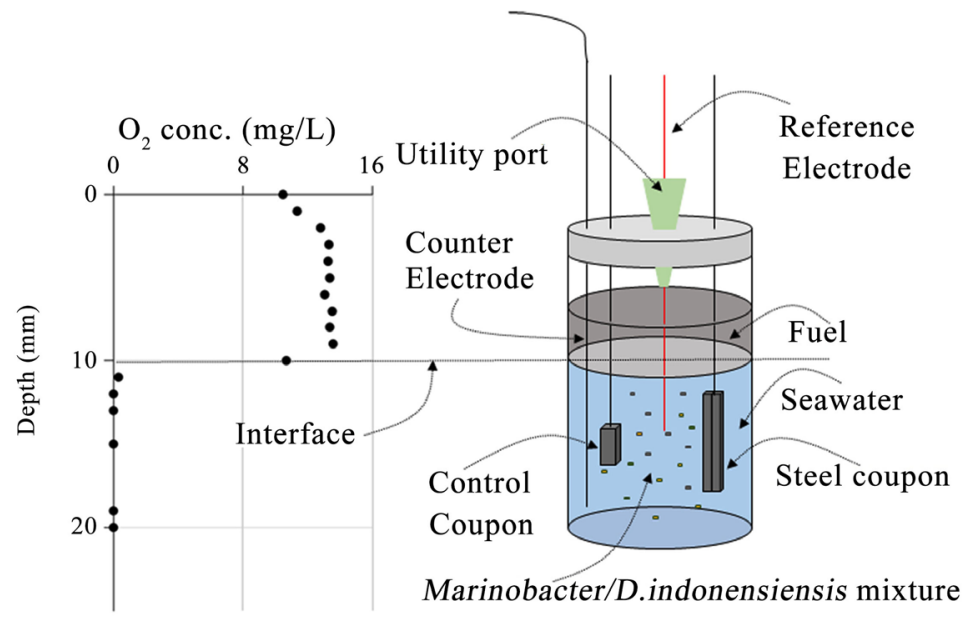

Figure 2. Schematic of the suboxic bioreactor utilized in corrosion experiments (right). Corroding samples (control and 1018 steel) are shown hanging from shielded wires. The control can be pure Fe or $\mathrm{Cu}_{70} \mathrm{Ni}_{30}$ alloy. Other components of the electrochemical cell are indicated. The seawater medium was inoculated with a mixture of Marinobacter $/ D$. indonensiensis. The fuel layer over the seawater was filter-sterilized JP5 fuel, and the seawater was non-sterilized San Diego Bay seawater. The ATP, dissolved oxygen, open circuit potential, linear polarization resistivity, and reduction potential of the medium were all measured several times a week. The seawater used for the ATP assay was replenished weekly. Also given is an oxygen concentration profile in ppm as a function of depth taken after the system reached a steady state suboxic condition and remained there (left). A sharp drop in the oxygen concentration as the seawater/fuel interface is crossed is easily seen. The system was kept exposed to the air via the utility port, which was also used for inserting an $\mathrm{Ag} / \mathrm{AgCl}$ electrode during our electrochemical measurements.

4 - $5 \mathrm{~mL}$ of JP5 fuel on top of $\sim 18 \mathrm{~mL}$ of either natural seawater from San Diego Bay or Key West, or in some cases artificial seawater, the Widdel medium [46]. Although chemical, biological, and electrochemical processes were monitored, including dissolved oxygen concentration, ATP, open-circuit potential, reduction potential, and linear polarization resistivity, during the corrosion process, for the purpose of this paper only the dissolved oxygen profile is relevant. Other measurements will be presented in a future publication with a focus on the corrosion products and rates. Wires insulated with Teflon sleeves were spot welded on the side of the corroding coupons and sealed with a marine-grade epoxy (MarineWeld ${ }^{\mathrm{TM}}$, J-B Weld Co.) before the coupons were exposed to the marine medium. A platinum wire was used as a counter-electrode, and a homemade removable $\mathrm{Ag} / \mathrm{AgCl}$ electrode was used as a reference electrode. The homemade reference electrode was calibrated against the commercial $\mathrm{Ag} / \mathrm{AgCl}$ electrode before use. Experiments using only Marinobacter were performed as a control to elucidate the corrosion process in the absence of $\mathrm{H}_{2} \mathrm{~S}$ in a suboxic environment. Also, as a control for pit initiation in carbon steel, in some experiments pure $\mathrm{Fe}$ coupons cut and polished perpendicular to the rolling direction were immersed in the corrosive medium alongside the 1018 coupons to monitor pit initiation (if any) on the pure Fe surfaces. Depending on the experiments the samples were exposed to the corrosive environment for $\sim 1$ to $\sim 6$ months. Identical coupons 
were glued back to back and sealed with the marine epoxy so that only the polished surfaces on the metal coupons were exposed to the corrosive medium. These polished surfaces were essentially identical in most experiments on the two sides, so that the corrosion current densities would be uniform and self-similar on both surfaces. Only analyses from the polished faces of these samples are reported here.

\subsection{Analysis}

Coupons were investigated using a scanning field emission electron microscope (FEM) from Zeiss (SUPRA 55VP, Carl Zeiss Micro-Imaging, GmpH, Gottingen) and integrated Auger NanoProbe (PHI-710) systems equipped with energy-dispersive X-ray (EDX)and electron backscatter diffraction (EBSD) analysis. Corrosion products were analyzed before they were removed; results of these will be published elsewhere; here we focus on the surface morphology beneath the deposits, which was analyzed after the corrosion deposits were removed by dipping the corroded surface into an acidic solution known as Clarke solution [11] [47] [48] for 5 seconds followed by a rinse with Nanopure water and drying with dry nitrogen. The Clarke solution was prepared according to ASTM standards by adding $3.5 \mathrm{~g}$ of hexamethylenetetramine to $1000 \mathrm{~mL}$ of $6 \mathrm{M} \mathrm{HCL}$ (HPLC grade) [47] [48]. In this manuscript we focus on the role of the metallurgy in localized corrosion. For this reason the spatial distribution of the manganese sulfide inclusions throughout the steel matrix is of great interest. We developed a scheme for mapping and counting MnS inclusions in the 1018 carbon steel coupons and report on their concentrations. It is important to emphasize here that the geometry of the MnS inclusions is highly asymmetric: they appear as stringers having lengths of hundreds of microns along the rolling direction of the steel bars but widths of a micron or less in the planes perpendicular to the rolling direction. These are sometimes referred to as MnS stringers in the literature. On close examination these stringers turned out to be very complex phases, and we address these issues in our future publication elsewhere. These stringers are formed during the hot rolling process after molten steel is left to solidify as explained in the Introduction. Because MnS is highly deformable, the stringers are formed during the hot rolling process, when the steel is still in the austenitic $(\gamma$-Fe) phase [12] [16] [18] [20].

\section{Results and Discussions}

\subsection{Mapping Residual Strain}

The localized residual strain left from the metallurgical history of a metal can be assessed by investigating the EBSD image of a clean 1018 coupon surface to demonstrate the degree of lattice-preferred orientation of adjacent grains and sub-grains, as shown in Figure 3. Panel A shows the Auger nanoprobe secondary electron image of a $10 \times 10 \mu \mathrm{m}^{2}$ region of a 1018 coupon. Panel B shows the Auger nanoprobe orientation image of area $\mathrm{A}$, but the sample is tilted by $70^{\circ}$. 


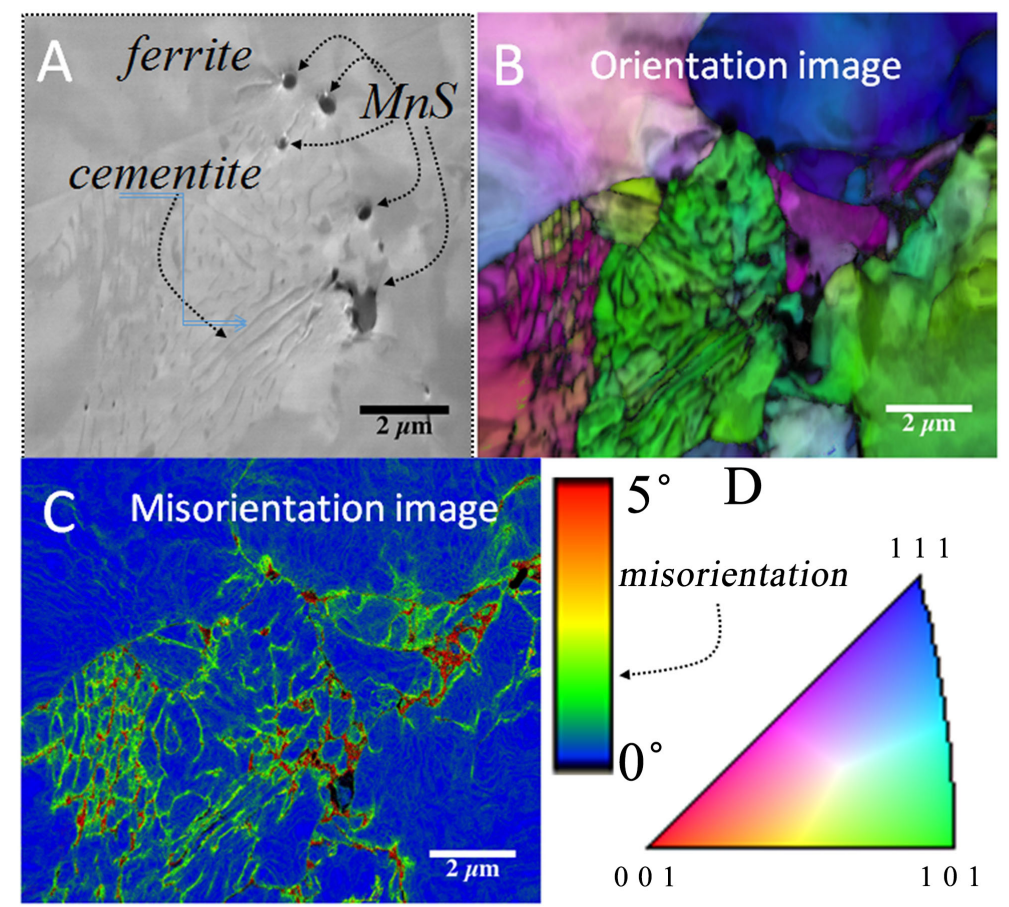

Figure 3. (A) Auger nanoprobe field emission secondary electron image of a 1018 coupon. (B) Auger nanoprobe EBSD orientation image shown in (A) but tilted by 70 degrees. (C) EBSD misorientation image generated from orientation image in (B). The sample was prepared by cutting the coupon perpendicular to the rolling axis of the rod and polishing to a $30-50 \mathrm{~nm}$ finish. (D) Orientation color legend associated with the image in (B) and misorientation color band associated with the image in (C). Indicated are $\mathrm{MnS}$ inclusions, pearlite bands and ferrite grains. Black represents unresolved points, indicating a region of high disorder. The misorientation map shows the locations of residual strain generated during the metallurgical preparation of the steel and hence of potential anodic sites. Shades of blue in ferrite grains and the colors green and red at defect sites indicate degrees of misorientation at these locations.

Various microstructures are marked in this panel including MnS inclusions, cementite phase, and ferrite grains. Panel C shows the EBSD misorientation image of the lattice-preferred orientation of grain aggregates generated from the orientation image in $\mathrm{B}$, where misorientations of grains of up to $5^{\circ}$ are mapped. There is a direct relation between the misorientation and the strain of the metal which can be correlated [5] [49]. In Panel D of Figure 3 we show the color correlations (legends) associated with the orientation indices (panel B) and misorientation angles of the grains (panel C). The sample was prepared by cutting the coupon perpendicular to the rolling direction of the rod and polishing to a $30-50 \mathrm{~nm}$ finish. Dark colors represent unresolved points, indicating a high degree of disorder. In principle a single grain should have a single solid color associated with a known orientation. The misorientation map shows the locations which have high residual strain [5] [49] and are potential anodic sites. It appears that the immediate surroundings of the MnS inclusions and the pearlite grains are highly strained and that these areas play a major role in localized corrosion [5] as well as in the overall corrosion of carbon steel that eventually leads to disastrous fail- 
ures in real-life applications. Misorientation maps have the potential to predict the locations of pitting corrosion before carbon steel is exposed to corrosive environments. Considering the detrimental role MnS inclusions play in localized corrosion it is instructive to determine their statistical distribution on 1018 carbon steel surfaces. This is presented next.

\subsection{Distribution of MnS Inclusions}

The FEM investigation of clean, polished coupon surfaces illustrates the major microstructures of interest in this study. FEM images of coupons cut parallel (right) and perpendicular (left) to the rolling direction are given in Figure 4. The perpendicular-cut sample was prepared the same as the parallel-cut sample as described above, but additionally was treated with Nitol in order to enhance the surface microstructures of interest. Nitol was used here only to emphasize these microstructures; it was not used on any other coupons that were subjected to the biocorrosive environment. In the image (left panel in Figure 4), the cross sections of the MnS stringers appear small $(\leq 1-\mu \mathrm{m}$ diameter) on the surface. Pearlite bands and grain boundaries are also clearly visible. The parallel-cut coupon was prepared by polishing to a $30-50 \mathrm{~nm}$ finish, following the procedure described above. This surface was not subjected to Nitol treatment to prevent etching of the MnS inclusions. As explained above, the microstructures of $\mathrm{MnS}$ inclusions and pearlite bands were stretched along the rolling direction of the steel rod. MnS appeared as long stringers stretching for hundreds of microns along the rolling direction, illustrating that the inclusions were long, pervasive features permeating throughout the material. Repeated investigation of 1018 carbon steel coupons using FEM in conjunction with EDX analysis gave the researchers familiarity with the appearance of the various mineral inclusions (MnS and others), so that they could be easily located and identified on surfaces. FEM imaging using low-energy primary electrons of $1 \mathrm{keV}$ (as in the left panel in Figure 4) show the MnS inclusions with dark rings around them. These dark rings are where the Nitol preferentially corroded the surface, leaving dark, shallow trenches in the boundary region between the inclusion and the surrounding iron matrix. Similarly, FEM imaging with an accelerating voltage of $20 \mathrm{kV}$, as in the case of the parallel-cut sample shown on the right in Figure 4, show the MnS inclusions as long, dark lines. Grain boundaries and bands of pearlite were ubiquitous throughout the steel, as seen in the perpendicular-cut sample. Without the Nitol treatment, these features were not as obvious in the FEM of polished clean surfaces.

The spatial distribution of MnS inclusions on 1018 coupons, cut and polished parallel and perpendicular to the rolling direction, was investigated using FEM imaging. The clean steel surface was treated with Clarke solution $(\mathrm{pH} \sim 1)$, which dissolved the MnS inclusions while leaving the rest of the steel surface unaffected [11]. This treatment left a distinct and easily recognizable depression of $30-50$ $\mathrm{nm}$ wherever there was a $\mathrm{MnS}$ inclusion whose top was dissolved away. These 


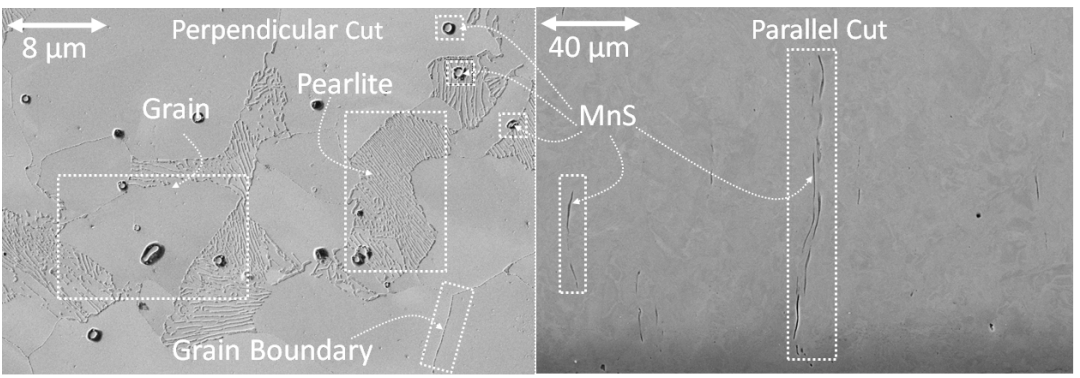

Figure 4. FEM images of clean carbon steel surfaces cut and polished perpendicular (left) and parallel (right) to the rolling axis of the rod. The image in the left panel was produced with a 1-kV accelerating voltage and etching with Nitol; the one in the right panel, with a $20-\mathrm{kV}$ accelerating voltage. Examples of individual ferrite crystalline grains, MnS inclusions, a grain boundary, and pearlite grains are indicated.

depressions (holes) appear as highly contrasted dark spots against a light background in the FEM image over a range of accelerating voltages between 1 and 20 $\mathrm{keV}$. MnS inclusions on perpendicular-cut samples appear as spots from less than a half to a few microns wide. On parallel-cut samples they appear as long stringers up to a few microns wide but hundreds of microns in length. In both cases images were taken in a grid pattern with FEM. We observed that the density of inclusions increased towards the outer edge of a coupon relative to the central region, which is in agreement with the literature [50]. The results presented here correspond to the overall average of all MnS inclusions.

On the parallel-cut sample, 125 fields of view (FOVs) were analyzed. These FOVs were distributed over a $5 \times 25$ grid in which rows of 25 images (lined up perpendicular to the rolling direction) were taken from 5 columns lined up along the rolling direction of the rod. Each image was taken at $1500 \times$ magnification and measured 170.8 microns along the rolling direction and 250.0 microns perpendicular to the rolling direction; in total they covered an area of $5.3 \mathrm{~mm}^{2}$. The FOVs on the surface cut and polished perpendicular to the rolling direction were taken 300 microns apart, while the FOVs associated with the coupons cut and polished along the rolling direction were taken $2 \mathrm{~mm}$ apart. This was to ensure that the same long MnS stringers were not counted multiple times among different FOVs. On the perpendicular-cut sample, 512 images were taken on a grid measuring 16 rows by 32 columns. Each image was taken at $5000 \times$ magnification and measured 75.3 by 46.0 microns, for a total analyzed area of $1.8 \mathrm{~mm}^{2}$.

The images were further processed in a Matlab program in which the MnS inclusions in a given FOV were identified and the Cartesian coordinates registered with the aid of the user. In the case of a perpendicular-cut sample, the MnS inclusions were identified and their locations entered into the program. This was done for each FOV, and a list of the coordinates of all inclusions was compiled. In the case of a parallel-cut sample, we assumed that the entire length of the inclusion was not necessarily visible in the surface plane of the sample. Therefore, we aligned the FOV such that the stringers ran parallel to the y-axis in the FEM images and identified just the $\mathrm{x}$-coordinate of the inclusion stringer. This was 
done for each FOV, and the list of coordinates of all inclusions was compiled. The accuracy of our visual identification was confirmed for a given coupon by performing an EDX analysis before the treatment with Clarke solution and comparing the results with those of visual inspection after the treatment. In this way the operator becomes familiar with these features and learns to identify them rapidly and accurately from their morphological signature in perpendicular- and parallel-cut samples in which inclusions are more or less the only features besides pearlite grains found on a polished surface.

The number of inclusions counted per FOV image in the perpendicular-cut sample is given as a histogram in Figure 5. The $\mathrm{x}$-axis gives the number of MnS inclusions counted per FOV, and the y-axis gives the fraction of the 512 images for which that number of stringer tips was found. The average was found to be $12 \pm 6$ inclusions per FOV image. This means a square $\mathrm{mm}$ area of 1018 carbon steel cut perpendicular to the rolling direction has on the average $\sim 3400$ inclusions, or each inclusion on the average occupies a $\sim 17 \times 17 \mu \mathrm{m}^{2}$ area.

In the case of the parallel-cut samples, the pertinent metric to describe the spatial distribution of the $\mathrm{MnS}$ inclusion stringers is the distance (perpendicular to the rolling direction, or $\mathrm{x}$-distance) between closest neighboring inclusions. A histogram of the distances between closest neighboring inclusion pairs is shown in Figure 6 (top). This distribution is compared with the histogram of closest paired MnS stringer tips compiled from the data associated with the surfaces cut and polished perpendicular to the rolling direction, also shown in Figure 6 (bottom). The maximum distance considered between pairs was chosen to match the size of the FOV utilized for the perpendicular-cut sample. This corresponds to a diagonal length of $88 \mu \mathrm{m}$ for the FOV images of the surface cut perpendicular to the rolling axis. Overall it was found that on average an inclusion stringer is within $\sim 18 \pm 16 \mu \mathrm{m}$ of another inclusion stringer.

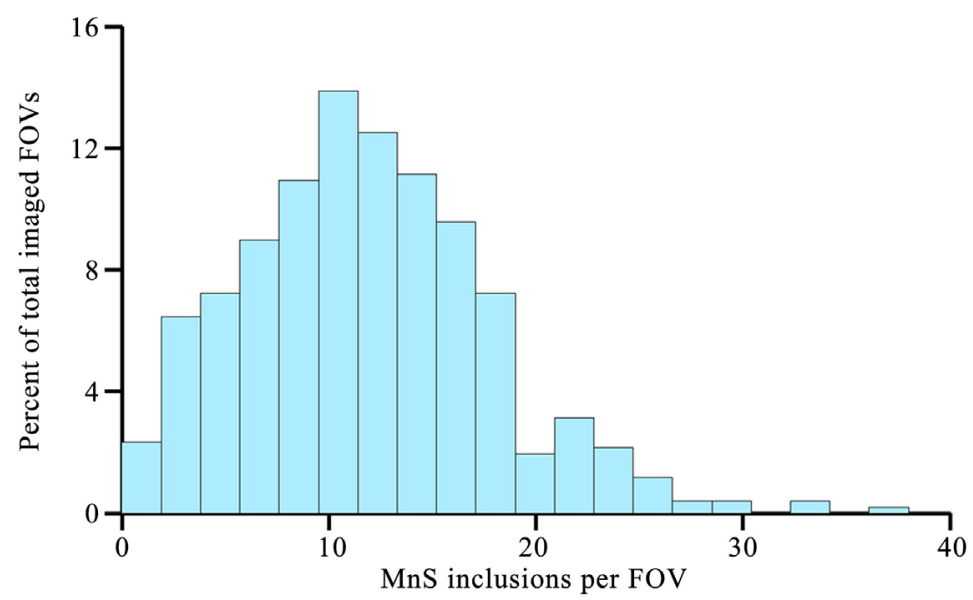

Figure 5. Histogram of the number of MnS stringer tips found per field of view (FOV) compiled from 512 images taken from a sample cut perpendicular to the rolling direction of the rod. The area of a single FOV was $3463.9 \mu \mathrm{m}^{2}$. The $\mathrm{x}$-axis gives the number of MnS stringer tips, and the $y$-axis gives the percentage of images found with that number of stringer tips exposed. 

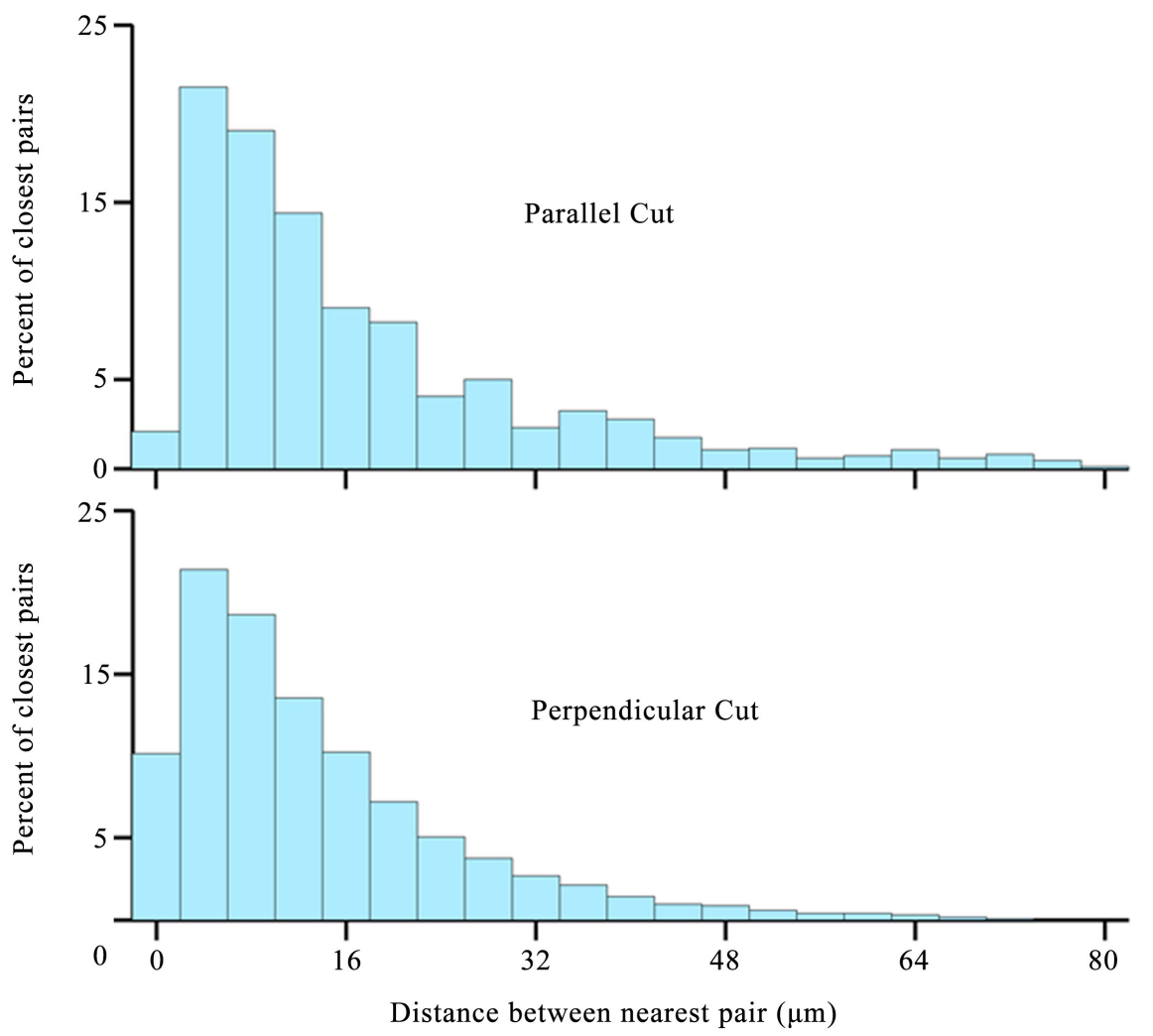

Figure 6. Histogram of distances between nearest neighbor pairs (both perpendicularand parallel-cut surfaces) as a fraction of total number of pairs per range of distance. Each bin on the $\mathrm{x}$-axis is $4 \mu \mathrm{m}$ wide. The two distributions are very similar, as expected.

The exponential decaying manner of the distribution in Figure 6 suggests that inclusion stringers were more often in tight groups than spread far apart. Figure 7 shows one of many FEM FOV images used to create the histogram for the parallel-cut coupons shown in Figure 6 (top). Here the channels left by dissolved MnS stringers appear as dark lines, while bands of pearlite stand out as white islands in the otherwise grey ferrite metal grains. Figure 7 shows that $\mathrm{MnS}$ stringers appeared to be often, but not always, localized along pearlite bands (Type A in Figure 7) and that in regions lacking in pearlite, stringers were observed less often (Type B in Figure 7). This reflects the difference between zones of the metal that possessed a high density of crystallographic disorder, or residual strain, and those that were more or less pure Fe grains, which were less strained. These highly strained ferrite zones will be more susceptible to localized corrosive attack and will serve as sacrificial anodes relative to the unstrained ferrite grains. This is a new view of corrosion, in which the anodic and cathodic sites on carbon steel are predetermined by its metallurgical history.

When pits are generated around adjacent $\mathrm{MnS}$ inclusions, they grow as deep tunnels burrowing down below the surface and they grow in radius [3] [4]. If the distance between two inclusions is within this pit radius, they will connect and coalesce. At a certain critical pit radius, pits combine to form a larger pit. We hypothesize that this average critical micro-pit radius is correlated to the average 
distance between inclusions. In the perpendicular-cut sample this average distance was found to be $14 \pm 12 \mu \mathrm{m}$. In the parallel-cut sample the average distance was $18 \pm 16 \mu \mathrm{m}$. We have more reliable statistics for the perpendicularly prepared surface because of its large sample size relative to the parallel-cut surface, for which statistics were gathered in only one dimension. It is, therefore, hypothesized that the critical average pit radius for the enhanced macro-pitting transition to occur is around $10-20 \mu \mathrm{m}$.

\subsection{Localized Corrosion}

When samples were removed from the corrosion reactors as described in Figure 2, the surfaces of the samples were covered with corrosion products, as shown in Figure 8. The surface illustrated in Figure 8 was exposed to a subox-

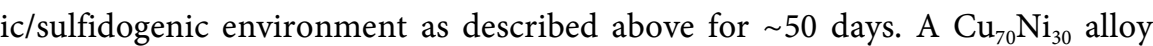
was coexposed with the carbon steel to simulate the pipes in Naval fuel tanks. The inset in Figure 8 shows an EDX spectrum obtained from the corrosion products. The $\mathrm{S}$ associated with the corrosion products, mostly FeS, was in sulfide form $\left(\mathrm{S}^{-2}\right)$ as confirmed by the XPS analysis. Because FeS is a conductive mineral it provides electrically conducting pathways from the carbon steel surface to the cathodic reactants $\left(\mathrm{O}_{2}, \mathrm{H}^{+}, \mathrm{HS}^{-}\right)$on the surface of corrosion products hence increasing the reach of cathodic processes and the rate of corrosions. The $\mathrm{Cu}$ and $\mathrm{Ni}$ signature in the EDX spectrum is due to corrosion products originating from the $\mathrm{CuNi}$ coupon (Figure 2). After the sample was removed, rinsed with Nanopure water and dried with dry nitrogen, it was analyzed using FEM. A large pit was obvious, but most of the other pits were obscured by thick corrosion deposits. In order to assess where the metal was eroding relative to any MnS inclusions, grain boundaries, and pearlite grains, as discussed above, the corrosion deposits on most of the surfaces were removed by dipping the corroded coupons into Clarke solution for a brief period ( $\sim 5 \mathrm{~s})$ before they were analyzed using FEM. On all the corroded coupons reported here, regardless of the corrosive environment, we observed excess localized corrosion in the immediate vicinity of MnS inclusions, in ferrite lamellae of pearlite bands and at many of the grain boundaries.

Once the corrosion products were removed, it became clear that the surface that was initially smooth to a $30-50 \mathrm{~nm}$ finish had become riddled with pits and crevices due to accelerated corrosion in these regions. We found that these regions were relatively predictable, based on the microstructures formed during the metallurgical preparation of the carbon steel. This is shown in Figure 9, where the localized corrosion is seen to follow the strained regions of the ferrite lattice. These areas include the pearlite bands and their surroundings, the grain boundaries between ferrite grains, and the immediate surroundings of $\mathrm{MnS}$ inclusions, all of which are shown in Figure 9. What is even more important is that where these microstructures intersected and co-located at specific points on the coupon surface, the rate of corrosion increased drastically with the density of lattice defects and dislocations, which made these locations more anodic than 
the unstrained regions of the ferrite grains and therefore more susceptible to localized corrosive attack.

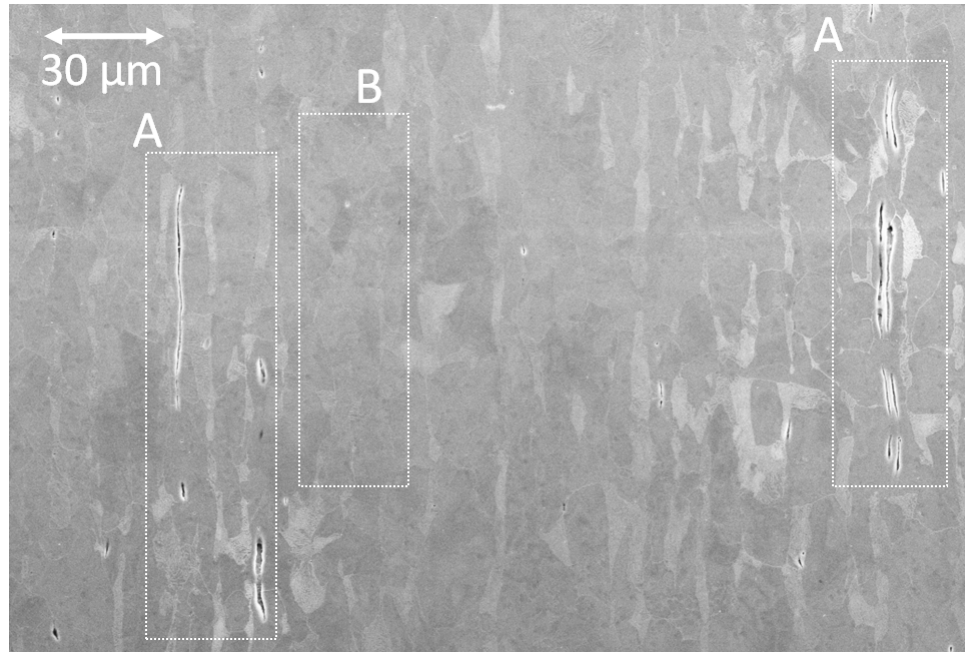

Figure 7. FEM image of pearlite bands (light regions) and elongated MnS stringers in a parallel-cut 1018 coupon. The sample was prepared by polishing to a $30-50 \mathrm{~nm}$ finish and then treating for five seconds with Clarke solution to dissolve the $\mathrm{MnS}$ inclusions exposed on the surface. The locations of MnS stringers appear in FEM images as dark lines. Pearlite appears as light regions in the slightly darker ferrite matrix. MnS inclusions were observed in the regions of high pearlite concentration (Type A regions) and were mostly absent in regions of pure ferrite (Type B regions). The Type A regions were highly strained compared to the Type B regions.

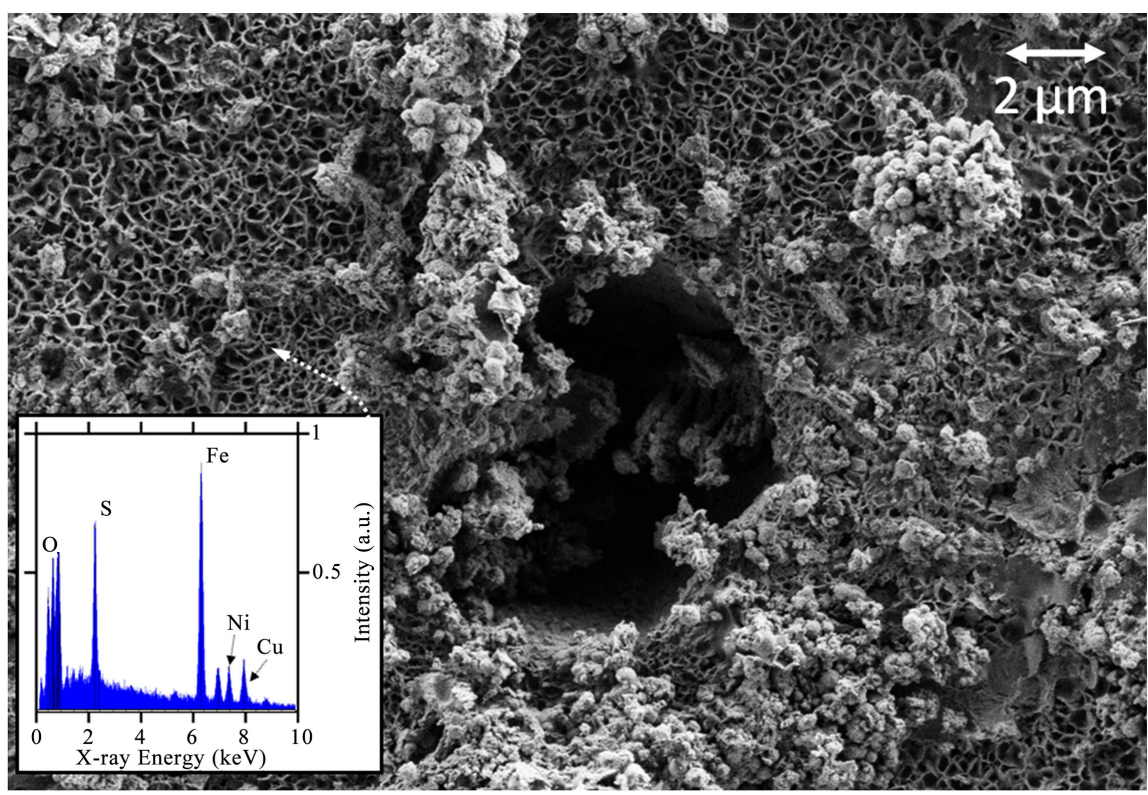

Figure 8. FEM image of a corrosion pit and its surroundings covered with corrosion products after 50 days of exposure to the suboxic/sulfidogenic environment described in the text. The inset shows an EDX spectrum identifying some of the corrosion products. The morphological features of the underlying metal are obscured by the corrosion deposits. These features were revealed by cleaning off the deposits by dipping the corroded surface briefly $(\sim 5 \mathrm{~s})$ into Clarke solution. 


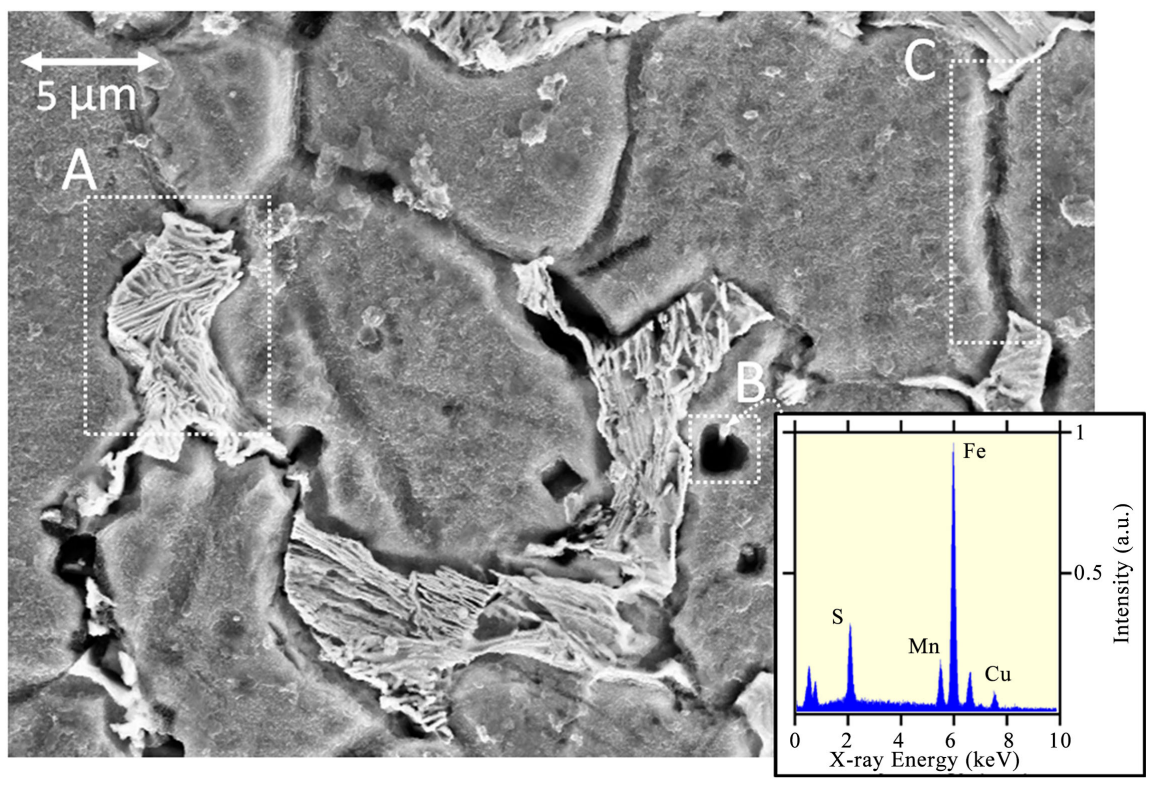

Figure 9. FEM image of corroded 1018 coupon cut perpendicular to the rolling direction after corrosion products were removed using Clarke solution. The sample was exposed to a suboxic/sulfidogenic environment for 50 days. Indicated are (A) pearlite, (B) a MnS stringer protruding from the pit, and $(\mathrm{C})$ grain boundaries with accelerated corrosion in the boundary region. The inset is an EDX spectrum taken from the tip of the MnS inclusion. A zoomed-in view of the MnS inclusion is shown in Figure 10.

The localized corrosion around MnS inclusions grew deeper and wider as it tunneled down beneath the sample surface along the length of the MnS stringers as reported in our previous work [3] [4] and illustrated in Figure 10: the inset in the right-hand corner of Figure 10 shows two EDX spectra, colored blue and yellow. The blue spectrum was taken from point $A$, while the yellow one was taken from the bottom of the pit at point $B$. The pit depth $(\sim 6 \mu \mathrm{m})$ was determined using the methodology reported in our earlier publication [4]. It is possible to see inside the pit, as long as it is not too deep, using contrast adjusted secondary electron imaging, as shown in the inset in the lower right-hand corner of Figure 10.

Analogous results may be seen in the case of coupons cut parallel to the rolling direction. Stringers exposed on the polished surface during the initial stages of corrosion produced excess corrosion along the entire length of their sides, as illustrated in Figure 11. The degree and severity of the corrosion depended on the local surroundings of the MnS inclusion. The surface in Figure 11 was exposed to the suboxic environment produced by anaerobe Marinobacter, the environment was not sulfidogenic. The presence of $\mathrm{H}_{2} \mathrm{~S}$ in solution exacerbated localized corrosion. An example of this is shown in the inset in the upper right corner of Figure 11. The surface associated with the inset image was exposed to a suboxic/sulfidogenic environment. Notice also that although the corrosion was initiated locally around the MnS inclusion, the presence of $\mathrm{H}_{2} \mathrm{~S}$ created localized pitting at the ferrite grain in the form of trenches and pits. This creates a positive 


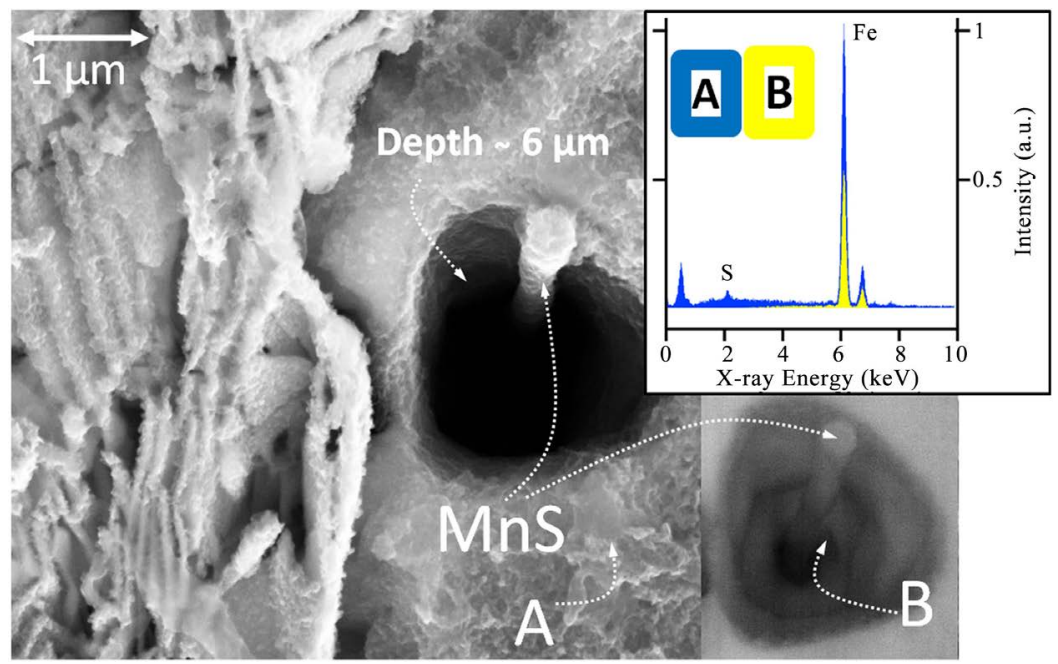

Figure 10. FEM image of the MnS stringer marked in Figure 9 and its surroundings. The surface was cut and polished perpendicular to the rolling direction, and corrosion products were removed using Clarke solution. The sample was exposed to the suboxic/sulfidogenic environment for 50 days. Marked are the MnS stringer sticking out of the pit and points $\mathrm{A}$ and $\mathrm{B}$, from which the EDX spectra shown in the inset (upper right-hand corner) were taken to determine the pit depth $(\sim 6 \mu \mathrm{m})$. The inset in the lower right corner is a backscattered contrast-adjusted image of the pit, where one can see the bottom of the pit. Such MnS inclusions eventually dissolve and produce localized $\mathrm{H}_{2} \mathrm{~S}$ and $\mathrm{S}$ as the acidity of the pit increases.

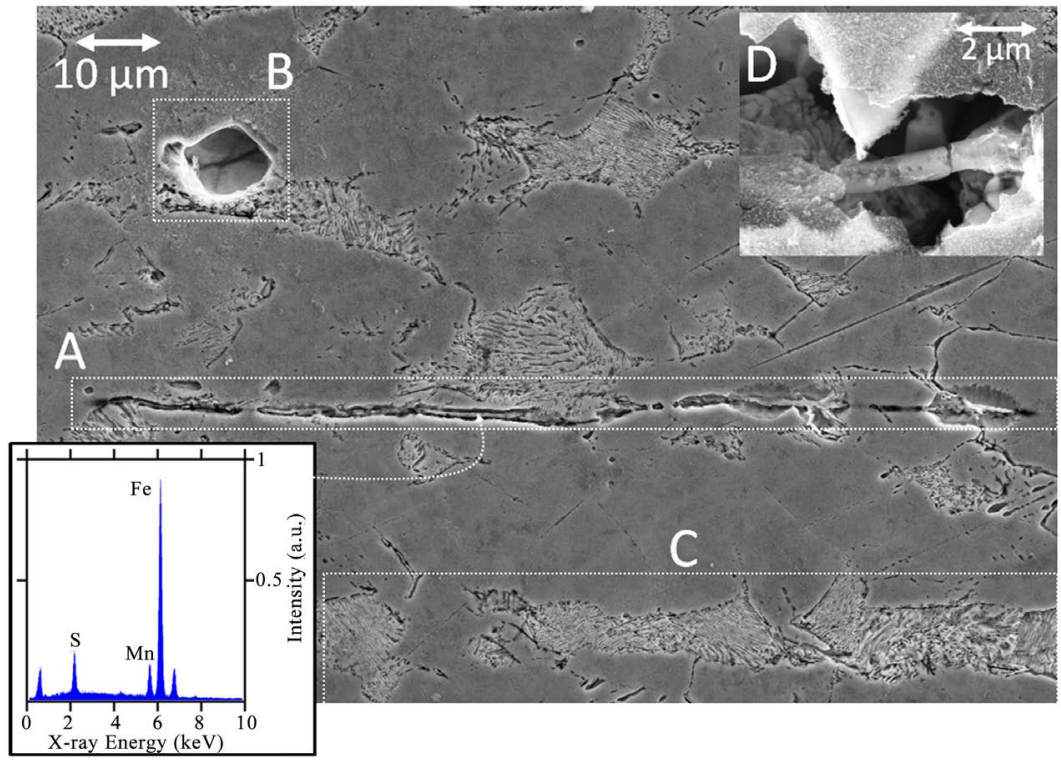

Figure 11. FEM image of a corroded 1018 coupon cut parallel to the rolling direction. The sample was exposed to a suboxic environment generated by Marinobacter in unfiltered San Diego seawater with $5 \mathrm{~mL}$ of JP5 fuel on top for 33 days and stripped in Clarke solution for approximately 5 seconds. Indicated are (A) a MnS stringer along the rolling direction with excess corrosion at the boundary and an EDX spectrum from a point on the MnS inclusion, (B) a corrosion pit growing in a region where pearlite and a grain boundary are co-located, $(\mathrm{C})$ a pearlite band along the rolling direction, and (D) a stringer which broke because of stress release when the iron matrix no longer supported the MnS stringer. 
feedback mechanism for local corrosion: as $\mathrm{H}_{2} \mathrm{~S} / \mathrm{S}$ is released, facilitating a cathodic process in the immediate surface area of the ferrite grains near the ferrite/MnS interface, and as the surface area of the ferrite is exposed, we hypothesize that the hydrolysis of Fe-ions in the region acidifies the local surroundings of the MnS stringer, which causes dissolution of MnS inclusions, causing the release of $\mathrm{H}_{2} \mathrm{~S} / \mathrm{S}$ abiotically, which then fuels the localized corrosion. It is important to emphasize here that pit initiation and pit growth are two entirely different electrochemical processes. Pit growth depends on whether or not there are highly strained regions in the area to generate and sustain a localized low $\mathrm{pH}$ level due to the hydrolysis of $\mathrm{Fe}^{+2,+3}$ ions [3] [4].

A broken MnS stringer, something that was commonly observed, is seen in the inset in Figure 11. When the immediate surroundings of a MnS stringer were corroded and etched away, a great amount of stress was released by the loss of ferrite matrix holding the stringer in place. The two ends of the break point separated and in some cases were no longer aligned after the MnS stringer assumed a less stressed configuration without the surrounding ferrite matrix holding it in place.

The density of lattice defects in the ferrite matrix increased in zones where pearlite and MnS inclusions intersected each other. The result was excessive localized corrosion. An example is given in Figure 12, where a pearlite grain appears to be co-located with a MnS inclusion that was initially buried under the surface. This coupon was cut and polished parallel to the rolling direction, from left to right. Notice that the pit initiated around a pearlite grain on the surface exposed the MnS inclusion below the surface to the corrosive environment. Subsequently the localized corrosion followed the MnS inclusion under the surface, creating a hole around the stringer and burrowing into the metal along the stringer. The corrosive environment was suboxic without any sulfate-reducing bacteria in the medium. Our observations point to the fundamental corrosion processes taking place in these systems, which do not depend upon the presence of sulfate-reducing bacteria (SRBs). Regardless of the particular corroding medium, the corrosion initiates and grows where there is strain in the iron lattice. Even though the corrosion illustrated in Figure 12 was not initiated by a sulfidogenic environment, the fact that dissolved $\mathrm{MnS}$ releases abiotic $\mathrm{H}_{2} \mathrm{~S}$ into the local environment of a pit means that the immediate surroundings of $\mathrm{MnS}$ inclusions become sulfidogenic abiotically, giving rise to accelerated corrosion within these deep, long, narrow regions.

Many factors accelerate or slow down the progress of corrosion; however, the metal is most susceptible to corrosion at anodic sides that preexisted on the surface because of the metallurgical preparation of the metal. Regardless of the environment (suboxic or suboxic/sulfidogenic) the corrosion always initiates at and grows from these defect sites.

Figure 13 illustrates another corrosion trench on a surface cut and polished parallel to the rolling direction. This time the corrosion was initiated along a 
grain boundary. Notice at the point marked A that there is a broken line of structure extending along the trench. When analyzed with EDX, this line of

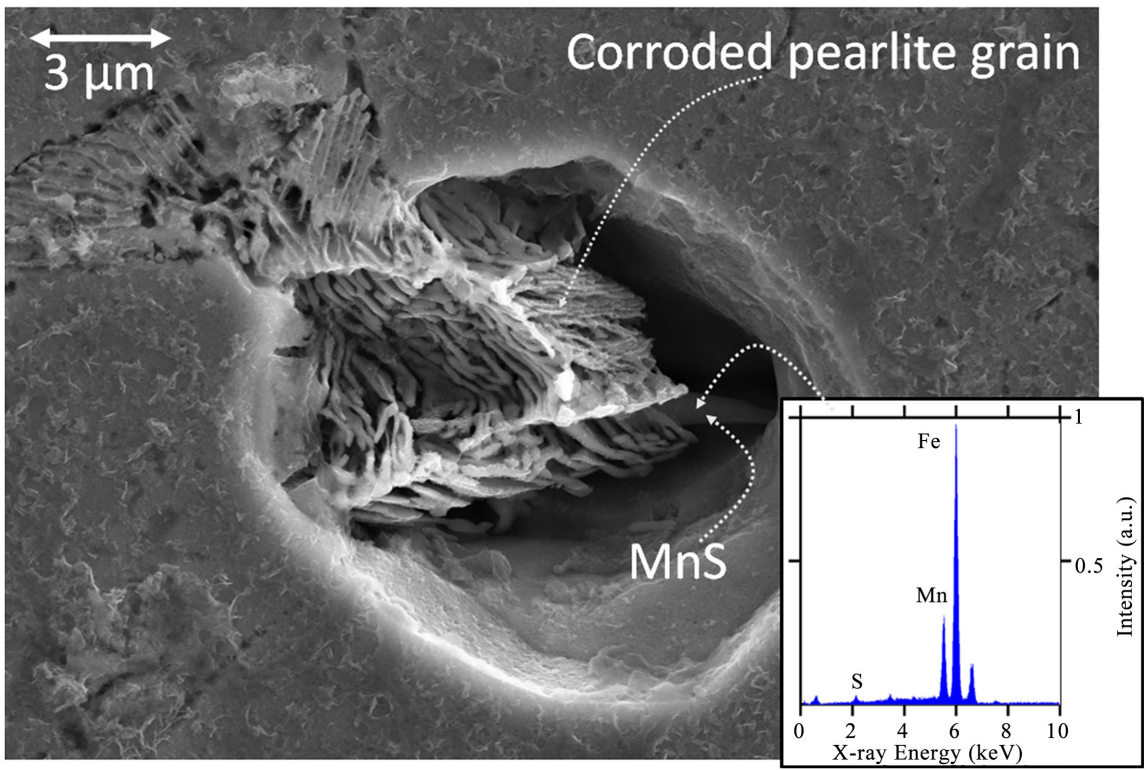

Figure 12. FEM image of a pit generated in and around a pearlite grain. This is the same surface as that shown in Figure 11, but a different region. The inset shows an EDX spectrum taken from a MnS inclusion exposed at the bottom of the pit, as marked. Notice the beginning of the hole around the MnS inclusion underneath the surface and extending along the MnS stringer.

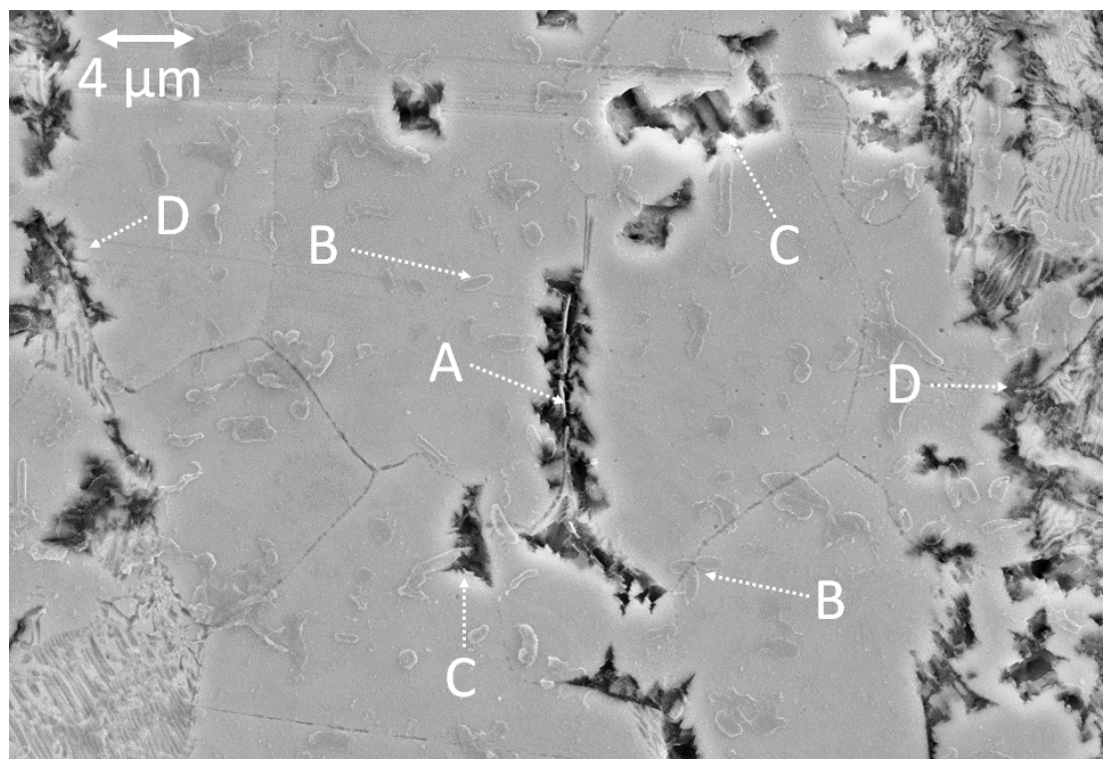

Figure 13. Excess corrosion at grain boundaries on a 1018 coupon surface. Indicated in the center is (A) a cementite lamella lined up with a grain boundary. EDX analysis at point A shows a nearly pure $\mathrm{Fe}$ signature. Also indicated are (B) examples of Marinobacter cells left behind, (C) grain boundary corrosion with no pearlite in the region, and (D) corrosion at grain boundaries and around pearlite grains. The sample was cut and polished parallel to the rolling direction and exposed for 33 days to the suboxic environment created by Marinobacter activity in San Diego Bay seawater. 
structure gave a signature of nearly pure Fe. This was most likely a cementite lamella localized along the grain boundary; EDX is not very sensitive to a $\mathrm{C}$ signature. In a corrosive environment, individual grains will etch out at different rates depending on the local density of lattice imperfections and differences in the orientation of the grains at grain boundaries. The particular grain boundary marked A in Figure 13 apparently intersected a pearlite grain, and it was one of the $\mathrm{Fe}_{3} \mathrm{C}$ lamellae running along the interface which caused the excess lattice strain in this region that resulted in enhanced localized corrosion. In this figure, we also notice a multitude of other grain boundaries exhibiting excessive localized corrosion which have pearlite grains nearby. These are marked D in the figure. Other grain boundaries, marked $\mathrm{C}$ in the figure, corroded at an accelerated rate without the nearby presence of pearlite or $\mathrm{MnS}$ inclusions.

Although this manuscript is not focused on distinguishing between suboxic and suboxic/sulfidogenic corrosion processes, it is worthwhile to mention some differences we have noticed. Figure 13 shows the morphology of a corroded surface exposed to the suboxic environment of Marinobacter for 33 days, and Figure 14 shows a similarly corroded surface exposed to the suboxic/sulfidogenic environment of Marinobacter/D. indonensiensis for 50 days. The morphology of the surface in Figure 14 is qualitatively similar to that shown in Figure 13, but there are noticeable differences between the two surfaces, principally that the localized attack was much more severe in the case of suboxic/sulfidogenic exposure. Comparing the scale bars in Figure 13 and Figure 14, one observes that suboxic/sulfidogenic exposure gave rise to deeper, wider localized corrosion pits and crevices. The corrosion was initiated at strained areas in both cases, with and without biotically produced sulfide, but it became more severe in the system with SRBs. In Figure 14 the majority of grain boundaries are not corroded, but some near pearlite grains or MnS stringers are severely etched away. These are marked with circles in the figure. This differs from the results in Figure 9 (sulfidogenic/suboxic exposure, perpendicular cut) which show all grain boundaries being preferentially etched relative to the bulk iron. As mentioned above, coupons of $\mathrm{CuNi}$ alloy were corroded alongside the 1018 coupons (Figure 2) in these experiments, and their corrosion was investigated as well. We noticed that in the case of corrosion in a suboxic/sulfidogenic environment, substantial dissolution of the $\mathrm{CuNi}$ resulted in the deposition of $\mathrm{Cu}$ and $\mathrm{Ni}$ corrosion products on the 1018 coupon surfaces (see inset in Figure 8). Only very limited, if any, corrosion of the $\mathrm{CuNi}$ alloy was observed in suboxic corrosive environments. Work on the corrosion products of $\mathrm{CuNi}$ and carbon steel will be published elsewhere.

\section{Conclusions}

The most important conclusion of this work is that the inhomogeneous distribution of strained and unstrained regions left behind by the metallurgy gives rise to an inhomogeneous distribution of a large number of micro-sized galvanic cells 
which, in a corrosive environment, cause the initiation and growth of localized corrosion. In what follows an expanded version of this idea is described. Figure 15 summarizes our conclusions. It compares a pure Fe coupon (99.995\% purity) (bottom) and a 1018 carbon steel coupon (top) that were corroded simultaneously under the same experimental conditions; the coupons were cut and polished perpendicular to the rolling direction and exposed to the same suboxic/sulfidogenic environment for 170 days. Notice that at the scale shown there are a large number of localized corrosion pits on the 1018 coupon, whereas there is hardly any localized corrosion on the pure Fe coupon. Deep crevices and holes exist on the 1018 coupon around pearlite features, and many of them contain $\mathrm{MnS}$ inclusions at their deepest points. With the exception of grain boundaries, pure Fe does not possess many of the localized defects, such as MnS inclusions or pearlite bands, that are abundantly present in 1018 carbon steel. Furthermore, this was not galvanic protection of pure Fe, for we have observed a lack of localized corrosion on pure $\mathrm{Fe}$ in many instances where pure Fe was co-exposed with a carbon steel coupon to a corrosive environment without physical contact with similar results.

Therefore, the only localized corrosion in the case of pure Fe is expected to be along the grain boundaries; we see such corrosion locally upon closer inspection.

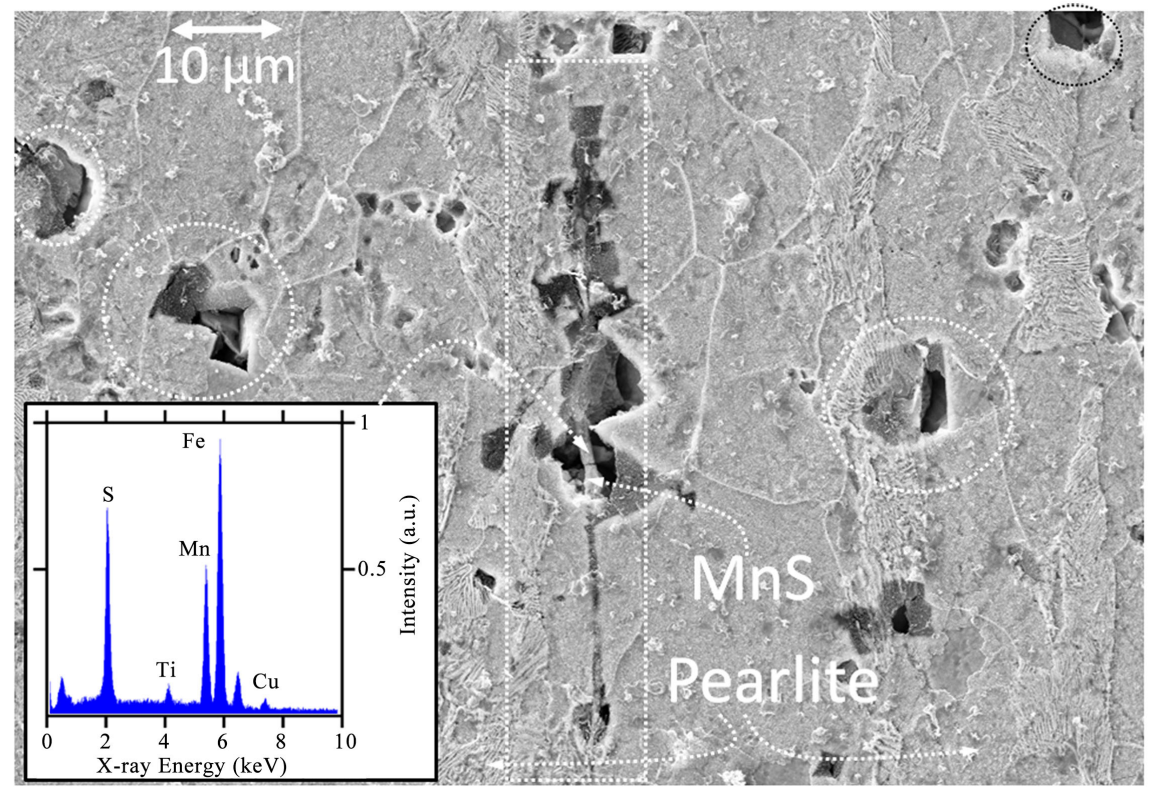

Figure 14. FEM image of accelerated corrosion around a MnS inclusion on a 1018 coupon surface cut parallel to the rod axis. The sample was corroded for 50 days in a Marinobacter/D. indonensiensis mixture in unfiltered San Diego seawater and $5 \mathrm{~mL}$ of JP5 fuel. The coupon was glued back to back to another 1018 coupon and corroded alongside a CuNi coupon. Corrosion products were removed by briefly immersing the coupon in Clarke solution. The inset shows an EDX spectrum taken from a MnS stringer as marked. The entire length of the inclusion is outlined by a box. Locations of grain boundary corrosion near pearlite grains are shown in circles. Notice also the excess corrosion at locations where broken $\mathrm{MnS}$, pearlite grains and ferrite iron were co-located. 


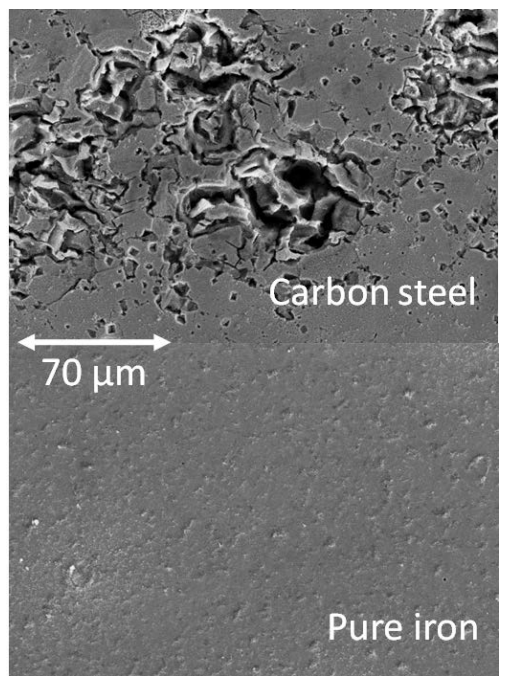

Figure 15. FEM images of corroded surfaces of a 1018 coupon (top) and a pure iron coupon (bottom), both cut perpendicular to the rolling direction, that were glued together back to back and corroded under identical suboxic/sulfidogenic conditions for 170 days in the presence of Marinobacter/D. indonensiensis in artificial seawater (Widdel medium) with JP5 fuel on top. The reason we used a pure Fe is that pure Fe does not have $\mathrm{MnS}$ inclusions and pearlite grains, which we claim is where most strains occur and most localized corrosion starts and propagates. Thus, theregions of accelerated corrosion are obvious as deep pits in the 1018 sample, but virtually nonexistent in the pure iron sample.

This comparison greatly clarifies the message that it is the defects and imperfections in the lattice of carbon steel that create anodic sites susceptible to corrosive attack. These defects are lacking in pure $\mathrm{Fe}$, and therefore the availability of anodic sites and severity of corrosion are limited. The corrosive environment does not control whether or where corrosion initiates, although this does control the rate and reactive pathway of corrosion. Metallurgical history plays a major role in determining where corrosion initiates. This forces us to formulate a new view of corrosion that considers the residual strain due to defects, imperfections, and mineral inclusions generated in the ferrite matrix as a result of the metallurgical preparation and alloying of the steel. The metallurgical history of steel leaves behind a distribution of strained and unstrained regions at the microscopic scale, this predetermines the locations of micro scale galvanic cells. The localized areas where the ferrite lattice is strained, depending on the density of dislocations and lattice defects, are the natural anodic sites. These are distributed within the Fe lattice in sizes ranging from the nano- to the microscale. The areas of the lattice that are not strained and are mostly intact without a high density of dislocations are the cathodic sites of the carbon steel. In this new view of corrosion the strained areas of the carbon steel act as sacrificial anodes for the unstrained regions of the same steel. The corrosion potential differences between the anodic and cathodic sites of the carbon steel can be calculated by means of the mechanochemistry approach introduced by Gutman many decades ago [51], and these can be compared quantitatively with the experimental measurements mentioned here. 
This new view of the corrosion of metals can be summarized as the volume of a metal being full of anodic and cathodic sites distributed with nano- and microscale separations. We hypothesize that this not only is true for carbon steel but is a fundamental fact that plays an important role in all metallic corrosion. In the case of low-carbon steels (1018 in particular), we identify these anodic sites as having high densities of dislocations in the immediate surroundings of $\mathrm{MnS}$ inclusions with a surface density of $\sim 3400 \mathrm{MnS}$ stringers per $\mathrm{mm}^{2}$, pearlite grains, and grain boundaries. Just as important is the fact that the magnitude of these anodic potential differences increases logarithmically with the density of dislocations [51], while the corrosion current density increases exponentially with the anodic potential differences. We further predict that if a metallic sample is highly strained but fairly uniform, these materials will be lacking localized galvanic coupling and will behave similarly to the unstrained pure metal with low density of pitting corrosion. We expect researchers and engineers will pay more attention to the metallurgical treatment of the alloys as they assess their corrosion properties.

\section{Acknowledgements}

This work is supported by ONR Multidisciplinary University Research Initiative (MURI) grant N00014-10-1-0946. The work is also supported in part by Montana State University funds supporting the Imaging and Chemical Analysis Laboratory (ICAL). The authors would like to acknowledge J. Martin for his contribution on dissolved oxygen measurements, L. Loetterle for her contribution to the microbiological aspects of this work, Prof. I. Beech of now Montana State University for providing and advising us on the Marinobacter cultures and $\mathrm{CuNi}$ alloys, members of Prof. J. Suflita's group at the University of Oklahoma for their help in providing and advising on San Diego Bay and Key West seawater, and L. Avci for her English editing. The help of L. Kellerman and N. Equall of ICAL in SEM analysis is greatly appreciated.

\section{Conflicts of Interest}

The authors declare no conflicts of interest regarding the publication of this paper.

\section{References}

[1] Costs, C. (2002) Preventive Strategies in the United States, Publication No. FHWA-RD-01-156, as Found in Supplement to Materials Performance.

[2] Jackson, J.E. (2016) Cost of Corrosion Annually in the US Over \$1.1 Trillion in 2016.

[3] Avci, R., et al. (2013) Mechanism of MnS-Mediated Pit Initiation and Propagation in Carbon Steel in an Anaerobic Sulfidogenic Media. Corrosion Science, 76, 267-274. https://doi.org/10.1016/j.corsci.2013.06.049

[4] Avci, R., et al. (2015) A Practical Method for Determining Pit Depths Using X-Ray Attenuation in EDX Spectra. Corrosion Science, 93, 9-18. 
https://doi.org/10.1016/j.corsci.2014.12.018

[5] Martin, J.D. (2014) Biocorrosion of 1018 Steel in Sulfide Rich Marine Environments; a Correlation between Strain and Corrosion Using Electron Backscatter Diffraction. In: Chemical Engineering, Montana State University, 175.

[6] Murr, L.E. (2015) A Brief History of Metals. Handbook of Materials Structures, Properties, Processing and Performance, 3-9.

[7] Kirk-Othmer (2004) Steel. In: Encyclopedia of Chemical Technology, V. 00, John Wiley \& Sons, New York.

https://onlinelibrary.wiley.com/doi/pdf/10.1002/0471238961.1920050516012420.a01 .pub2

[8] Brandt, D.A. and Warner, J.C. (2009) Metallurgy Fundamentals, Goodheart-Willcox.

[9] Lehmann, J. and Nadif, M. (2011) Interactions between Metal and Slag Melts: Steel Desulfurization. Reviews in Mineralogy and Geochemistry, 73, 493-511. https://doi.org/10.2138/rmg.2011.73.15

[10] Porter, D.A. and Easterling, K.E. (1992) Phase Transformation in Metals and Alloys. CRC Press. https://doi.org/10.1007/978-1-4899-3051-4

[11] Davis, B.H. (2013) Anaerobic Pitting Corrosion of Carbon Steel in Marine Sulfidogenic Environments. In: Physics, Montana State University, Bozeman.

[12] Krauss, G. (2003) Solidification, Segregation, and Banding in Carbon and Alloy Steels. Metallurgical and Materials Transactions B, 34, 781-792.

https://doi.org/10.1007/s11663-003-0084-Z

[13] Behrens, H. and Webster, J.D. (2011) Studies of Sulfur in Melts-Motivations and Overview. Reviews in Mineralogy and Geochemistry, 73, 1-8.

https://doi.org/10.2138/rmg.2011.73.1

[14] Choudhary, S. and Ghosh, A. (2008) Thermodynamic Evaluation of Formation of Oxide-Sulfide Duplex Inclusions in Steel. ISIJ International, 48, 1552-1559. https://doi.org/10.2355/isijinternational.48.1552

[15] Choudhary, S.K. (2012) Thermodynamic Evaluation of Inclusion Formation during Cooling and Solidification of Low Carbon Si-Mn Killed Steel. Materials and Manufacturing Processes, 27, 925-929. https://doi.org/10.1080/10426914.2011.602797

[16] Ito, Y., Masumitsu, N. and Matsubara, K. (1981) Formation of Manganese Sulfide in Steel. Transactions of the Iron and Steel Institute of Japan, 21, 477-484. https://doi.org/10.2355/isijinternational1966.21.477

[17] Kimura, S., et al. (2002) In-Situ Observation of the Precipitation of Manganese Sulfide in Low-Carbon Magnesium-Killed Steel. Metallurgical and Materials Transactions A, 33, 427-436. https://doi.org/10.1007/s11661-002-0103-8

[18] Yu, H., et al. (2006) Morphology and Precipitation Kinetics of MnS in Low-Carbon Steel during Thin Slab Continuous Casting Process. Journal of Iron and Steel Research, International, 13, 30-36. https://doi.org/10.1016/S1006-706X(06)60091-5

[19] Sun, W., Militzer, M. and Jonas, J. (1992) Strain-Induced Nucleation of MnS in Electrical Steels. Metallurgical Transactions A, 23, 821-830. https://doi.org/10.1007/BF02675559

[20] Liu, Z., et al. (2006) Morphology Control of Copper Sulfide in Strip Casting of Low Carbon Steel. ISIJ International, 46, 744-753. https://doi.org/10.2355/isijinternational.46.744

[21] Oikawa, K., et al. (1995) The Control of the Morphology of MnS Inclusions in Steel during Solidification. ISIJ International, 35, 402-408. 
https://doi.org/10.2355/isijinternational.35.402

[22] Rieders, N., et al. (2018) New Insights into the Role of MnS Inclusions in the Localized Corrosion of 1018 Carbon Steel.

[23] Baker, M. and Castle, J. (1993) The Initiation of Pitting Corrosion at MnS Inclusions. Corrosion Science, 34, 667-682. https://doi.org/10.1016/0010-938X(93)90279-P

[24] Spitzig, W. (1983) Effect of Sulfides and Sulfide Morphology on Anisotropy of Tensile Ductility and Toughness of Hot-Rolled C-Mn Steels. Metallurgical Transactions $A, 14,471-484$. https://doi.org/10.1007/BF02644224

[25] Spitzig, W. (1983) Effect of Sulfide Inclusion Morphology and Pearlite Banding on Anisotropy of Mechanical Properties in Normalized C-Mn Steels. Metallurgical Transactions A, 14, 271-283. https://doi.org/10.1007/BF02651624

[26] Spitzig, W. and Sober, R. (1981) Influence of Sulfide Inclusions and Pearlite Content on the Mechanical Properties of Hot-Rolled Carbon Steels. Metallurgical Transactions A, 12, 281-291. https://doi.org/10.1007/BF02655201

[27] Gainer, L. and Wallwork, G. (1979) The Effect of Nonmetallic Inclusions on the Pitting of Mild Steel. Corrosion, 35, 435-443.

https://doi.org/10.5006/0010-9312-35.10.435

[28] Cyril, N., Fatemi, A. and Cryderman, B. (2008) Effects of Sulfur Level and Anisotropy of Sulfide Inclusions on Tensile, Impact, and Fatigue Properties of SAE 4140 Steel. SAE Technical Paper.

[29] Luu, W. and Wu, J. (1995) Effects of Sulfide Inclusion on Hydrogen Transport in Steels. Materials Letters, 24, 175-179.

https://doi.org/10.1016/0167-577X(95)00068-2

[30] Ju, C., Don, J. and Rigsbee, J. (1986) A High Voltage Electron Microscopy Study of Hydrogen-Induced Damage in a Low Alloy, Medium Carbon Steel. Materials Science and Engineering, 77, 115-123. https://doi.org/10.1016/0025-5416(86)90359-9

[31] Ju, C. and Rigsbee, J. (1985) The Role of Microstructure for Hydrogen-Induced Blistering and Stepwise Cracking in a Plain Medium Carbon Steel. Materials Science and Engineering, 74, 47-53. https://doi.org/10.1016/0025-5416(85)90109-0

[32] Ju, C. and Rigsbee, J. (1988) Interfacial Coherency and Hydrogen Damage in Plain Carbon Steel. Materials Science and Engineering. A, 102, 281-288. https://doi.org/10.1016/0025-5416(88)90583-6

[33] Sephton, M. and Pistorius, P. (2000) Localized Corrosion of Carbon Steel Weldments. Corrosion, 56, 1272-1279. https://doi.org/10.5006/1.3280516

[34] Reformatskaya, I., et al. (2004) The Effect of Nonmetal Inclusions and Microstructure on Local Corrosion of Carbon and Low-Alloyed Steels. Protection of Metals, 40, 447-452. https://doi.org/10.1023/B:PROM.0000043062.19272.c5

[35] Wranglen, G. (1974) Pitting and Sulphide Inclusions in Steel. Corrosion Science, 14, 331-349. https://doi.org/10.1016/S0010-938X(74)80047-8

[36] Adhikari, A., et al. (2008) Electrochemical Behavior and Anticorrosion Properties of Modified Polyaniline Dispersed in Polyvinylacetate Coating on Carbon Steel. Electrochimica Acta, 53, 4239-4247. https://doi.org/10.1016/j.electacta.2007.12.069

[37] Chen, C., et al. (2017) Insight into the Anti-Corrosion Performance of Electrodeposited Silane/Nano- $\mathrm{CeO}_{2}$ Film on Carbon Steel. Surface and Coatings Technology, 326, 183-191. https://doi.org/10.1016/j.surfcoat.2017.06.031

[38] Park, J.H. and Park, J.M. (2014) Electrophoretic Deposition of Graphene Oxide on 
Mild Carbon Steel for Anti-Corrosion Application. Surface and Coatings Technology, 254, 167-174. https://doi.org/10.1016/j.surfcoat.2014.06.007

[39] Quezada-Rentería, J.A., Cházaro-Ruiz, L.F. and Rangel-Mendez, J.R. (2017) Synthesis of Reduced Graphene Oxide (rGO) Films onto Carbon Steel by Cathodic Electrophoretic Deposition: Anticorrosive Coating. Carbon, 122, 266-275. https://doi.org/10.1016/j.carbon.2017.06.074

[40] Santana, I., et al. (2015) Corrosion Protection of Carbon Steel by Silica-Based Hybrid Coatings Containing Cerium Salts: Effect of Silica Nanoparticle Content. Surface and Coatings Technology, 265, 106-116. https://doi.org/10.1016/j.surfcoat.2015.01.050

[41] Suresh, S., et al. (2018) Evaluation of Corrosion Resistance of Nano Nickel Ferrite and Magnetite Double Layer Coatings on Carbon Steel. Thin Solid Films, 645, 77-86. https://doi.org/10.1016/j.tsf.2017.10.032

[42] Ye, X., et al. (2015) Protecting Carbon Steel from Corrosion by Laser in Situ Grown Graphene Films. Carbon, 94, 326-334. https://doi.org/10.1016/j.carbon.2015.06.080

[43] Zavareh, M.A., et al. (2014) Plasma Thermal Spray of Ceramic Oxide Coating on Carbon Steel with Enhanced Wear and Corrosion Resistance for Oil and Gas Applications. Ceramics International, 40, 14267-14277. https://doi.org/10.1016/j.ceramint.2014.06.017

[44] Prasai, D., et al. (2012) Graphene: Corrosion-Inhibiting Coating. ACS Nano, 6, 1102-1108. https://doi.org/10.1021/nn203507y

[45] Krishnamurthy, A., et al. (2015) Superiority of Graphene over Polymer Coatings for Prevention of Microbially Induced Corrosion. Scientific Reports, 5, Article No. 13858. https://doi.org/10.1038/srep13858

[46] Widdel, F. and Bak, F. (1992) The Prokaryotes: A Handbook on the Biology of Bacteria: Ecophysiology, Isolation, Identification, and Applications. Springer-Verlag, New York.

[47] Lizama, S.A.W.Y. (2015) Clarke's Solution Cleaning Used for Corrosion Product Removal: Effects on Carbon Steel Substrate, in Corrosion and Prevention 2015. Australasian Corrosion Association, Adelaide.

[48] ASTM (2017) Standard Practice for Preparing, Cleaning, and Evaluating Corrosion Test Specimens, in G1. West Conshohocken.

[49] Kamaya, M. (2009) Measurement of Local Plastic Strain Distribution of Stainless Steel by Electron Backscatter Diffraction. Materials Characterization, 60, 125-132. https://doi.org/10.1016/j.matchar.2008.07.010

[50] Hwang, B., et al. (2005) Analysis and Prevention of Side Cracking Phenomenon Occurring during Hot Rolling of Thick Low-Carbon Steel Plates. Materials Science and Engineering: A, 402, 177-187. https://doi.org/10.1016/j.msea.2005.04.045

[51] Gutman, E.M. (1998) Mechanochemistry of Materials. Cambridge International Science Publishing, Cambridge. 